$\begin{array}{cc}\text { ACADEMIA ROMÂNĂ } & \text { Rev. Roum. Chim., } \\ \text { 2019, 64(8), 687-710 } \\ \text { Revue Roumaine de Chimie } \\ \text { http://web.icf.ro/rrch/ }\end{array}$

\title{
DESIGN, SYNTHESIS AND IN VITRO ANTI-BACTERIAL ACTIVITIES OF BENZOFURAN-ISATIN HYBRIDS
}

\author{
Yin-Ling WANG ${ }^{\mathrm{a},}$, Shi-Jia ZHAO ${ }^{\mathrm{b}}$, Yi LIU ${ }^{\mathrm{b}}$ and Zhi XU ${ }^{\mathrm{a},{ }^{*}}$ \\ ${ }^{a}$ Huanghuai University, Zhumadian, P R China \\ ${ }^{\mathrm{b}}$ Wuhan University of Science and Technology, Wuhan, P R China
}

Received November 18, 2018

A series of novel benzofuran-isatin hybrids $\mathbf{6 a - x}$ tethered through propylene, butylene, pentylene and hexylene were designed, synthesized and evaluated for their in vitro antibacterial activities against a panel of clinically important Grampositive and Gram-negative pathogens including drug-resistant bacteria. All hybrids exhibited decent in vitro anti-bacterial activities, and the most active hybrid $\mathbf{6 l}$ was not only comparable to vancomycin against the majority of the tested Gram-positive strains, but also highly active against Gram-negative bacteria. Based on the above results, hybrid $\mathbf{6} \mathbf{1}$ could act as a lead for further investigation. Moreover, the enriched structure-activity relationship may pave the way for further optimization

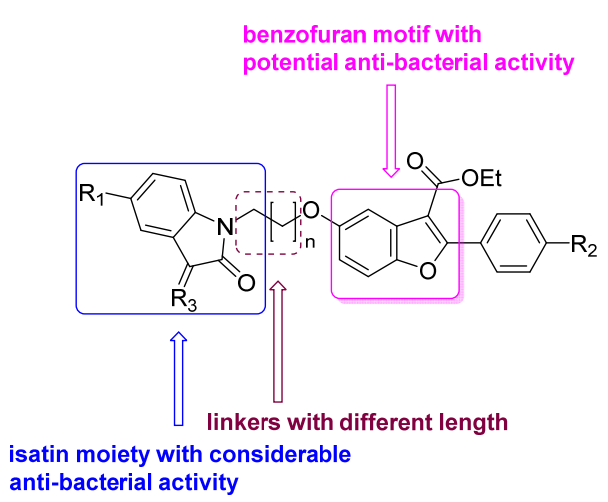

isatin moiety with considerable anti-bacterial activity

\section{INTRODUCTION}

Bacterial infections are responsible for the majority of both hospital-acquired and community-acquired infections. ${ }^{1,2}$ Staphylococcus aureus/S. aureus, Staphylococcus epidermidis/S. epidermidis, Streptococcus pneumonia/S. pneumonia, Enterococcus faecalis/E. faecalis and Enterococcus faecium/E. faecium are clinically important Grampositive pathogens, and Escherichia coli/E. coli and Pseudomonas aeruginosa/P. aeruginosa are the common Gram-negative bacteria. Drug-resistant organisms which generate due to the long-term, broad, inappropriate use and even abuse of antibiotics poses an ever-growing health concern, and around 700,000 deaths occurred annually due to the drugresistant pathogens. ${ }^{3,4}$

The benzofuran and isatin motifs are ubiquitous in nature, and their derivatives possess a variety of pharmacological properties such as anti-cancer, ${ }^{5,6}$ anti-viral, ${ }^{7}$ anti-Alzheimer's disease, ${ }^{8}$ antitubercular $^{9,10}$ and anti-bacterial ${ }^{11,12}$ activities. Moreover, some of isatin and benzofuran based compounds such as sunitinib, nintedanib, benzbromarone and amiodarone have already used in clinics or under clinical trials for the treatment various diseases, so benzofuran and isatin derivatives play a pivotal role in the development of new drugs.

Molecular hybridization, has the potential to overcome cross resistance, improvement of affinity and efficacy compared to the parent drugs, represents a promising strategy in the development of new drugs. ${ }^{13,14}$ The benzofuran and isatin derivatives have the anti-bacterial potential, so it's reasonable to evaluate the anti-bacterial activity of benzofuran-isatin hybrids.

\footnotetext{
*Corresponding author: ochemistry@163.com
} 


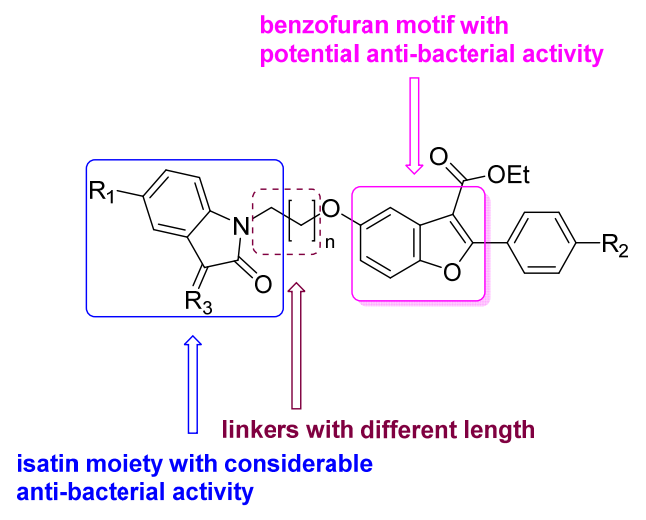

Fig. 1 - Design strategy for benzofuran-isatin hybrids tethered via different linkers.

Based on the facts stated above and as a continuous program to develop novel anti-bacterial candidates, a series of novel benzofuran-isatin hybrids 6a-x tethered via different length alkyl linkers were designed, synthesized and evaluated for their in vitro anti-bacterial activities against a panel of clinically important Gram-positive and Gram-negative pathogens including drug-resistant bacteria in this study. The design strategy was depicted in Figure 1.

\section{RESULTS AND DISCUSSION}

\section{Synthesis}

All of the desired benzofuran-isatin hybrids 6a$\mathbf{x}$ can be achieved by the synthetic route depicted in Scheme 1. 5-Methoxyisatin/5-fluoroisatin/isatin 1a-c were alkylated with 1,3-dibromopropane, 1,4dibromobutane, 1,5-dibromopentane and 1,6dibromohextane 2a-d provided $N$-(3-bromopropyl/ 4-bromobutyl/5-bromopentyl/6-bromohexyl)isatin derivatives 3a-i with yields $62-76 \%{ }^{15}$ The benzofuran intermediate 5a-c was obtained by cyclization of ethyl 3-(4-substituted phenyl)-3oxopropanoate 4a-c and benzoquinone with copper (II) triflate $\left(\mathrm{Cu}(\mathrm{OTf})_{2}\right)$ as catalyst. ${ }^{16}$ Treatment of isatin derivatives 3a-i and benzofuran intermediates 5a-c with potassium carbonate as base generated the desired benzofuran-isatin hybrids 6a-m (58$83 \%$ ). Finally, condensations of $\mathbf{6 a - m}$ with the corresponding amine hydrochlorides in the presence of sodium bicarbonate gave the rest benzofuran-isatin hybrids 6i-x (18-73\%). The chemical structures of targets $\mathbf{6 a - x}$ were listed in Table 1.

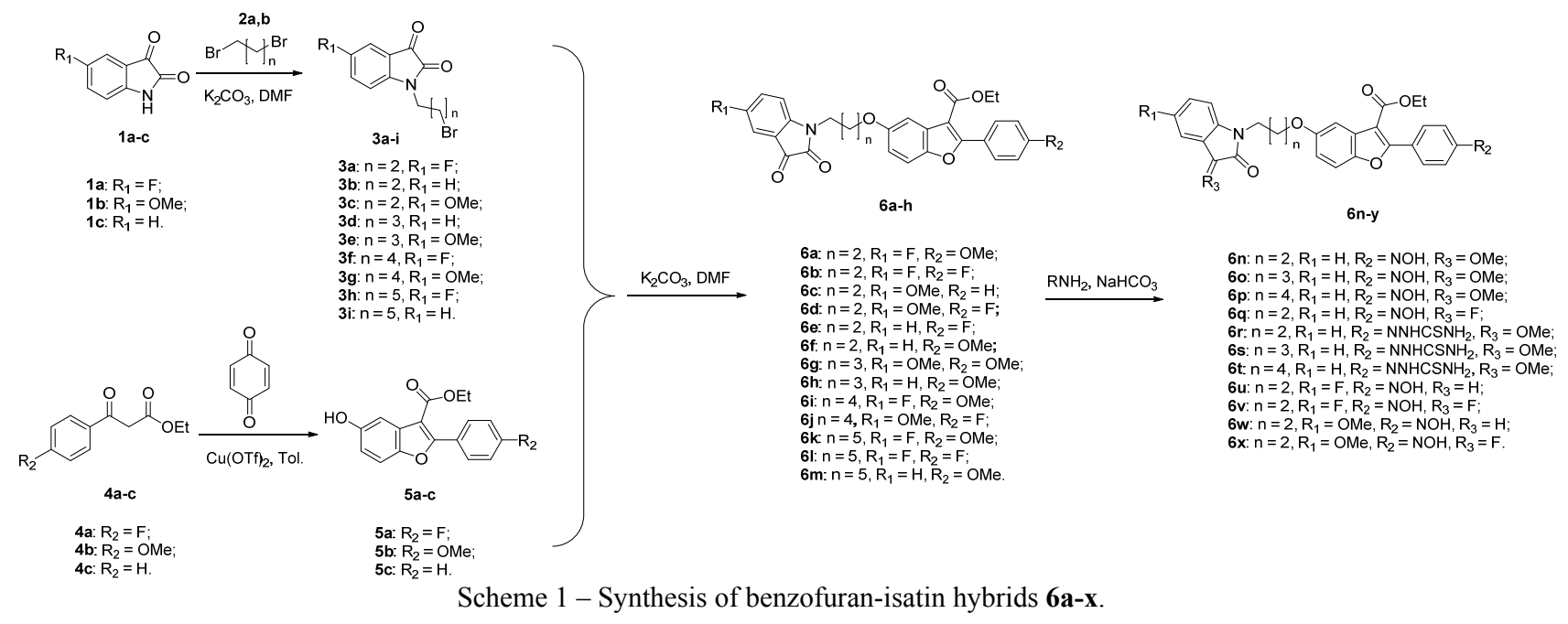

Table 1

Chemical structures of benzofuran-isatin hybrids 6a-x<smiles>[R]COc1ccc2oc(-c3ccc([R2])cc3)c(C(=O)OCC)c2c1</smiles>

$6 a-x$

\begin{tabular}{ccccc}
\hline Compounds & $\mathbf{n}$ & $\mathbf{R}_{\mathbf{1}}$ & $\mathbf{R}_{\mathbf{2}}$ & $\mathbf{R}_{\mathbf{3}}$ \\
\hline $\mathbf{6 a}$ & 2 & $\mathrm{~F}$ & $\mathrm{OMe}$ & $\mathrm{O}$ \\
$\mathbf{6 b}$ & 2 & $\mathrm{~F}$ & $\mathrm{~F}$ & $\mathrm{O}$ \\
$\mathbf{6 c}$ & 2 & $\mathrm{OMe}$ & $\mathrm{H}$ & $\mathrm{O}$ \\
\hline
\end{tabular}




\begin{tabular}{|c|c|c|c|c|}
\hline & & & \multicolumn{2}{|c|}{ Table 1 (continued) } \\
\hline 6d & 2 & $\mathrm{OMe}$ & $F$ & $\mathrm{O}$ \\
\hline $6 e$ & 2 & $\mathrm{H}$ & F & $\mathrm{O}$ \\
\hline of & 2 & $\mathrm{H}$ & $\mathrm{OMe}$ & $\mathrm{O}$ \\
\hline $6 \mathrm{~g}$ & 3 & $\mathrm{OMe}$ & $\mathrm{OMe}$ & $\mathrm{O}$ \\
\hline $6 h$ & 3 & $\mathrm{H}$ & $\mathrm{OMe}$ & $\mathrm{O}$ \\
\hline $\mathbf{6 i}$ & 4 & $\mathrm{~F}$ & $\mathrm{OMe}$ & $\mathrm{O}$ \\
\hline $\mathbf{6 j}$ & 4 & $\mathrm{OMe}$ & $\mathrm{F}$ & $\mathrm{O}$ \\
\hline $6 \mathbf{k}$ & 5 & $\mathrm{~F}$ & $\mathrm{OMe}$ & $\mathrm{O}$ \\
\hline 61 & 5 & $\mathrm{~F}$ & $\mathrm{~F}$ & $\mathrm{O}$ \\
\hline $6 m$ & 5 & $\mathrm{H}$ & $\mathrm{OMe}$ & $\mathrm{O}$ \\
\hline $6 n$ & 2 & $\mathrm{H}$ & $\mathrm{NOH}$ & $\mathrm{OMe}$ \\
\hline 60 & 3 & $\mathrm{H}$ & $\mathrm{NOH}$ & $\mathrm{OMe}$ \\
\hline $6 p$ & 4 & $\mathrm{H}$ & $\mathrm{NOH}$ & $\mathrm{OMe}$ \\
\hline $6 \mathbf{q}$ & 2 & $\mathrm{H}$ & $\mathrm{NOH}$ & $\mathrm{F}$ \\
\hline $6 r$ & 2 & $\mathrm{H}$ & $\mathrm{NNHCSNH}_{2}$ & $\mathrm{OMe}$ \\
\hline 6s & 3 & $\mathrm{H}$ & $\mathrm{NNHCSNH}_{2}$ & $\mathrm{OMe}$ \\
\hline $6 t$ & 4 & $\mathrm{H}$ & $\mathrm{NNHCSNH}_{2}$ & $\mathrm{OMe}$ \\
\hline $6 u$ & 2 & $\mathrm{~F}$ & $\mathrm{NOH}$ & $\mathrm{H}$ \\
\hline $6 v$ & 2 & $\mathrm{~F}$ & $\mathrm{NOH}$ & $\mathrm{F}$ \\
\hline $6 w$ & 2 & $\mathrm{OMe}$ & $\mathrm{NOH}$ & $\mathrm{H}$ \\
\hline $6 x$ & 2 & $\mathrm{OMe}$ & $\mathrm{NOH}$ & $\mathrm{F}$ \\
\hline
\end{tabular}

Table 2

In vitro antibacterial activity of benzofuran-isatin hybrids 6a-x against Gram-positive strains

\begin{tabular}{|c|c|c|c|c|c|c|}
\hline \multirow{2}{*}{ Compd. } & \multicolumn{6}{|c|}{ MIC $(\mu \mathrm{g} / \mathrm{mL})$} \\
\hline & MSSE & MRSE & MSSA & MRSA & E.fa. & E.fm. \\
\hline $\mathbf{6 a}$ & 0.5 & 2 & 2 & 1 & 8 & 32 \\
\hline $6 b$ & 1 & 1 & 2 & 2 & 4 & 8 \\
\hline $6 c$ & 1 & 2 & 2 & 1 & 2 & 16 \\
\hline 6d & 2 & 2 & 8 & 4 & 8 & 32 \\
\hline $6 e$ & 4 & 1 & 2 & 2 & 1 & 8 \\
\hline $6 f$ & 1 & 2 & 1 & 1 & 1 & 16 \\
\hline $6 g$ & 0.5 & 2 & 2 & 2 & 8 & 64 \\
\hline $6 \mathrm{~h}$ & 2 & 4 & 8 & 4 & 4 & 16 \\
\hline $6 i$ & 1 & 8 & 2 & 2 & 4 & 64 \\
\hline $6 \mathbf{j}$ & 2 & 4 & 8 & 4 & 8 & 16 \\
\hline $6 \mathbf{k}$ & 1 & 8 & 2 & 2 & 2 & 16 \\
\hline 61 & 0.25 & 4 & 1 & 1 & 2 & 8 \\
\hline $6 \mathrm{~m}$ & 1 & 4 & 1 & 2 & 2 & 16 \\
\hline $6 n$ & 2 & 8 & 4 & 8 & 16 & 32 \\
\hline 60 & 2 & 4 & 4 & 4 & 8 & 16 \\
\hline $6 p$ & 1 & 2 & 2 & 2 & 4 & 32 \\
\hline $6 q$ & 2 & 2 & 8 & 4 & 8 & 32 \\
\hline $6 r$ & 8 & 8 & 16 & 8 & 16 & 64 \\
\hline $6 s$ & 16 & 8 & 8 & 8 & 16 & 32 \\
\hline $6 t$ & 8 & 16 & 16 & 32 & 64 & 128 \\
\hline $6 u$ & 4 & 8 & 4 & 2 & 8 & 16 \\
\hline $6 v$ & 2 & 8 & 2 & 4 & 8 & 32 \\
\hline $6 w$ & 1 & 2 & 4 & 4 & 4 & 64 \\
\hline $6 x$ & 4 & 8 & 4 & 2 & 8 & 32 \\
\hline CPFX & 0.125 & 4 & 0.25 & 0.25 & 0.5 & 8 \\
\hline VAN & 1 & 1 & 0.5 & 1 & 4 & 1 \\
\hline
\end{tabular}

Abbreviations: MSSE, methicillin-sensitive Staphylococcus epidermidis; MRSE, methicillinresistant Staphylococcus epidermidis; MSSA, methicillin-sensitive Staphylococcus aureus; MRSA, methicillin-resistant Staphylococcus aureus; E.fa., Enterococcus faecalis ATCC; E.fm., Enterococcus faecium; CPFX, ciprofloxacin; VAN, vancomycin.

\section{Anti-bacterial activity}

All benzofuran-isatin hybrids $\mathbf{6 a - x}$ were evaluated for their in vitro antibacterial activities against a panel of Gram-positive and Gram- negative pathogens. ${ }^{17,18}$ The minimum inhibitory concentration (MIC) is defined as the minimum concentration of compound required to give $90 \%$ inhibition of bacterial growth. The results were listed in Tables 2 and 3, respectively. 
Table 3

In vitro antibacterial activity of benzofuran-isatin hybrids 6a-x against Gram-negative strains

\begin{tabular}{|c|c|c|c|c|c|c|c|c|}
\hline \multirow{2}{*}{ Compd. } & \multicolumn{8}{|c|}{ MIC $(\mu \mathrm{g} / \mathrm{mL})$} \\
\hline & E.co. & K.p. & P.a. & A.c. & E.c. & E.a. & P.m. & C.f. \\
\hline $6 a$ & 0.5 & 1 & 8 & 4 & 2 & 2 & 0.5 & 1 \\
\hline $6 \mathbf{b}$ & 0.25 & 2 & 4 & 4 & 1 & 1 & 2 & 0.25 \\
\hline $6 c$ & 0.5 & 1 & 8 & 8 & 0.5 & 1 & 2 & 2 \\
\hline 6d & 1 & 4 & 8 & 2 & 1 & 4 & 8 & 4 \\
\hline $6 e$ & 0.25 & 2 & 1 & 2 & 4 & 2 & 0.5 & 1 \\
\hline $6 f$ & 0.5 & 4 & 4 & 1 & 2 & 1 & 1 & 2 \\
\hline $6 \mathrm{~g}$ & 1 & 8 & 1 & 4 & 2 & 0.5 & 2 & 2 \\
\hline $6 h$ & 0.5 & 1 & 1 & 1 & 0.25 & 1 & 0.5 & 1 \\
\hline $6 \mathbf{i}$ & 0.25 & 2 & 8 & 8 & 1 & 1 & 0.25 & 1 \\
\hline $6 \mathbf{j}$ & 0.25 & 0.5 & 2 & 1 & 0.5 & 0.25 & 0.125 & 0.5 \\
\hline $6 \mathbf{k}$ & 0.125 & 1 & 4 & 4 & 0.5 & 0.25 & 0.125 & 1 \\
\hline 61 & 0.06 & 0.5 & 4 & 2 & 0.125 & 0.5 & 0.125 & 0.25 \\
\hline $6 \mathrm{~m}$ & 0.25 & 1 & 2 & 4 & 0.5 & 0.125 & 0.06 & 0.06 \\
\hline $6 n$ & 2 & 4 & 8 & 4 & 2 & 4 & 8 & 16 \\
\hline 60 & 4 & 8 & 8 & 16 & 4 & 2 & 4 & 8 \\
\hline $6 p$ & 4 & 4 & 8 & 4 & 2 & 8 & 4 & 16 \\
\hline $6 q$ & 2 & 4 & 4 & 8 & 4 & 8 & 4 & 8 \\
\hline $6 r$ & 4 & 16 & 8 & 32 & 16 & 16 & 32 & 64 \\
\hline $6 s$ & 8 & 4 & 16 & 16 & 32 & 32 & 64 & 64 \\
\hline $6 \mathrm{t}$ & 4 & 16 & 16 & 32 & 64 & 32 & 64 & 64 \\
\hline $6 u$ & 2 & 4 & 4 & 8 & 2 & 4 & 8 & 8 \\
\hline $6 v$ & 1 & 8 & 4 & 2 & 4 & 2 & 4 & 8 \\
\hline $6 w$ & 4 & 2 & 8 & 4 & 8 & 1 & 8 & 16 \\
\hline $6 x$ & 2 & 4 & 8 & 8 & 2 & 2 & 16 & 4 \\
\hline CPFX & 0.06 & 0.5 & 0.25 & 0.5 & 0.06 & 0.06 & $\leq 0.03$ & 0.03 \\
\hline
\end{tabular}

Abbreviations: E.co., Escherichia coli; K.p., Klebsiellapneumoniae; P.a., Pseudomonas aeruginosa ATCC 27853; A.c., Acinetobactercal coacetious; E.c., Enterobacter cloacae; E.a., Enterobacter aerogenes; P.m., Proteus mirabilis; C.f., Citrobacter freundii; CPFX, ciprofloxacin.

It can be concluded from Tables 2 and 3 that benzofuran-isatin hybrids $\mathbf{6 a - x}$ possess broadspectrum anti-bacterial activities, and MIC values were $0.25-128 \mu \mathrm{g} / \mathrm{mL}$ and $0.06-64 \mu \mathrm{g} / \mathrm{mL}$ against Gram-positive and Gram-negative pathogens, respectively. It is worth to notice that the activity of benzofuran-isatin hybrids 6a-x against MRSA and MRSE was equal to that of against MSSA and MSSE, indicating that these hybrids could be used to treat infections caused by drug-resistant bacteria. The SAR results suggested that introduction of hydroxylimine and thiosemicarbazide at C-3 position of isatin moiety was detrimental to the anti-bacterial activity, and the relative contribution order was ketone $>$ hydroxylimine $>$ thiosemicarbazide. The length of the linker has great influence on the activity, and the longer linker was more favorable than the shorter one especially against Gran-negative pathogens.

Among them, hybrids 6b,l (MIC: 0.25$8 \mu \mathrm{g} / \mathrm{mL}$ ) were comparable to vancomycin against the majority of the tested Gram-positive strains, and four hybrids $\mathbf{6 j}-\mathbf{m}$ (MIC: $0.06-4 \mu \mathrm{g} / \mathrm{mL}$ ) were highly active against Gram-negative bacteria especially against Escherichia coli, Enterobacter cloacae, Enterobacter aerogenes, Proteus mirabilis, and Citrobacter freundii.

\section{EXPERIMENTAL}

$\mathrm{N}$-(3-bromopropyl/4-bromobutyl/5-bromopentyl)isatin derivatives 3a-f (yield: 63-81\%) and ethyl 2-(4-substituted phenyl)-5-(prop-2-yn-1-yloxy)benzofuran-3-carboxylate 5a-c were synthesized via literature methods.

A mixture of $\mathrm{N}$-(3-bromopropyl/4-bromobutyl/5bromopentyl)isatin derivatives 3a-f $(1.0 \mathrm{mmol})$, ethyl 2-(4substituted phenyl)-5-(prop-2-yn-1-yloxy)benzofuran-3carboxylate 5a-c $(1.0 \mathrm{mmol})$ and $\mathrm{K}_{2} \mathrm{CO}_{3}(3.0 \mathrm{mmol})$ in DMF $(20 \mathrm{~mL})$ was stirred at room temperature for $48 \mathrm{~h}$. After filtration, the filtrate was concentrated under reduced pressure. The residue was purified by silica gel column chromatography with PE:EA=1:1 to give the precursors 6a-h.

The mixture of $\mathbf{6 a}-\mathbf{h}(1 \mathrm{mmol})$, sodium bicarbonate ( $2 \mathrm{mmol})$, and hydroxylamine hydrochloride or thiosemicarbazide hydrochloride $(1.5 \mathrm{mmol})$ dissolving in water $(10 \mathrm{~mL})$ and tetrahydrofuran (THF, $30 \mathrm{~mL}$ ) was stirred at $60{ }^{\circ} \mathrm{C}$ for $12 \mathrm{~h}$. After cooling to room temperature, the mixture was extracted with EA $(20 \mathrm{~mL} \times 3)$. The combined organic layers were washed with water $(50 \mathrm{~mL} \times 2)$ and brine $(50 \mathrm{~mL})$, and then dried over $\mathrm{Na}_{2} \mathrm{SO}_{4}$. After filtration, the filtrate was concentrated under reduced pressure to give a residue, which was further purified by silica gel chromatography eluted with PE: $\mathrm{EA}=1: 8$ to give the desired benzofuran-isatin-hydroxylimine/-thiosemicarbazide hybrids 7a-l. 
5-(3-(5-fluoro- 2,3-dioxoindolin-1-yl)propoxy)-2-(4-methoxyphenyl)benzofuran-3-carboxylate (6a)

Yellow solid, yield: $69 \%$. ${ }^{1} \mathrm{H}$ NMR $\left(400 \mathrm{MHz}, \mathrm{DMSO}-d_{6}\right) \delta$ $1.33\left(3 \mathrm{H}, \mathrm{t}, J=4.0 \mathrm{~Hz}, \mathrm{CO}_{2} \mathrm{CH}_{2} \mathrm{CH}_{3}\right), 2.11(2 \mathrm{H}, \mathrm{t}, J=4.0 \mathrm{~Hz}$, $\left.-\mathrm{CH}_{2}-\right), 3.85\left(3 \mathrm{H}, \mathrm{s}, \mathrm{OCH}_{3}\right), 3.89\left(2 \mathrm{H}, \mathrm{t}, J=4.0 \mathrm{~Hz},-\mathrm{CH}_{2}-\right)$, $4.12\left(2 \mathrm{H}, \mathrm{t}, J=4.0 \mathrm{~Hz},-\mathrm{CH}_{2}-\right), 4.33(2 \mathrm{H}, \mathrm{q}, J=4.0 \mathrm{~Hz}$,
$\left.\mathrm{CO}_{2} \mathrm{CH}_{2} \mathrm{CH}_{3}\right), 6.94(1 \mathrm{H}, \mathrm{dd}, J=4.0 \mathrm{~Hz}, \mathrm{Ar}-\mathrm{H}), 7.09(2 \mathrm{H}, \mathrm{d}$, $J=4.0 \mathrm{~Hz}, \mathrm{Ar}-\mathrm{H}), 7.25-7.28(1 \mathrm{H}, \mathrm{m}, \mathrm{Ar}-\mathrm{H}), 7.39(1 \mathrm{H}, \mathrm{d}$, $J=4.0 \mathrm{~Hz}, \mathrm{Ar}-\mathrm{H}), 7.45-7.50(2 \mathrm{H}, \mathrm{m}, \mathrm{Ar}-\mathrm{H}), 7.57(1 \mathrm{H}, \mathrm{d}$, $J=8.0 \mathrm{~Hz}, \mathrm{Ar}-\mathrm{H}), 7.94-7.97$ (2H, m, Ar-H). ESI-MS m/z: 540 $[\mathrm{M}+\mathrm{Na}]^{+}$.

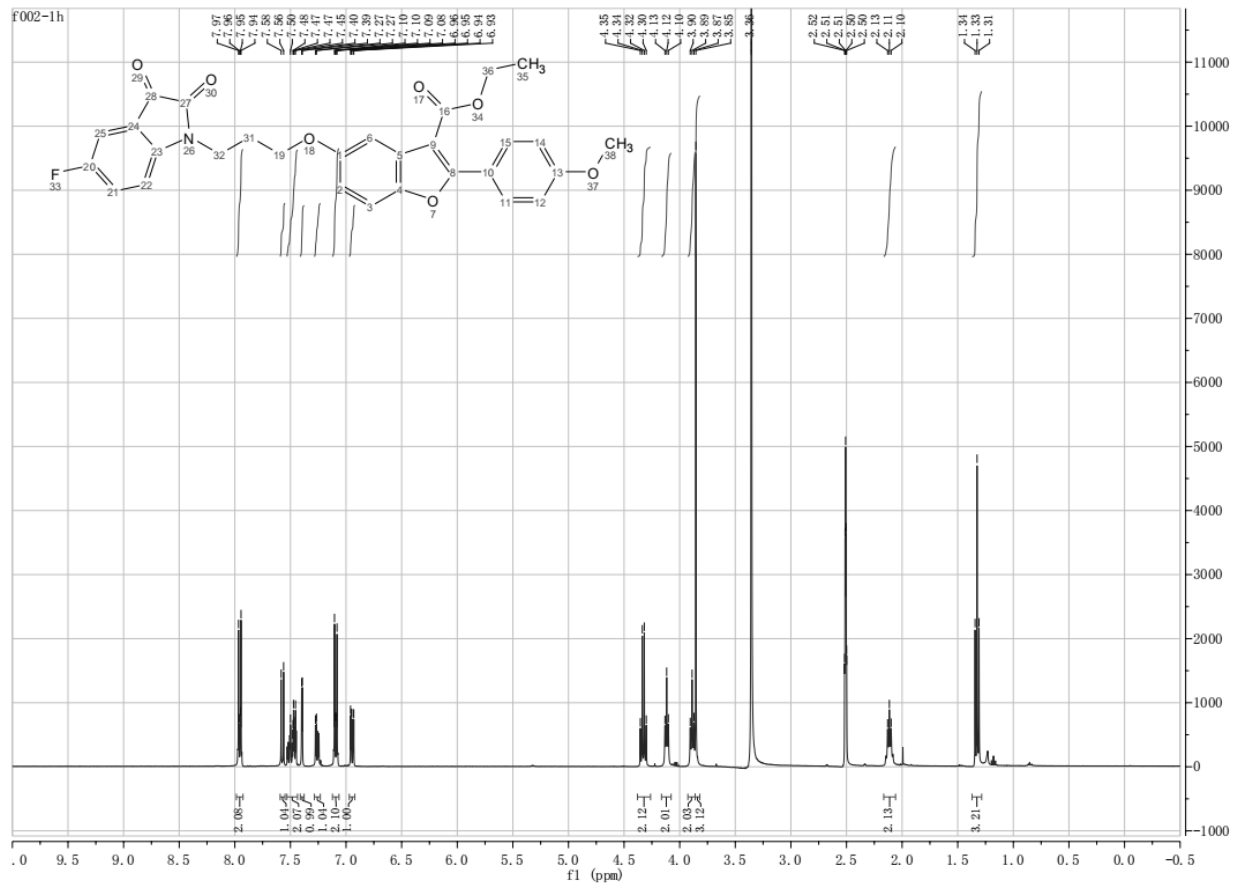

5-(3-(5-fluoro-2,3-dioxoindolin-1-yl)propoxy)-2-(4-fluorophenyl) benzofuran-3-carboxylate (6b)

Yellow solid, yield: $77 \% .{ }^{1} \mathrm{H}$ NMR (400 MHz, DMSO- $\left.d_{6}\right) \delta 1.31$ $\left(3 \mathrm{H}, \mathrm{t}, J=8.0 \mathrm{~Hz}, \mathrm{CO}_{2} \mathrm{CH}_{2} \mathrm{CH}_{3}\right), 2.12\left(2 \mathrm{H}, \mathrm{t}, J=4.0 \mathrm{~Hz},-\mathrm{CH}_{2}-\right)$, $3.89\left(2 \mathrm{H}, \mathrm{t}, J=4.0 \mathrm{~Hz},-\mathrm{CH}_{2}-\right), 4.12\left(2 \mathrm{H}, \mathrm{t}, J=4.0 \mathrm{~Hz},-\mathrm{CH}_{2}-\right)$, $4.32\left(2 \mathrm{H}, \mathrm{q}, J=8.0 \mathrm{~Hz}, \mathrm{CO}_{2} \mathrm{CH}_{2} \mathrm{CH}_{3}\right), 6.98(1 \mathrm{H}, \mathrm{dd}, J=4.0,8.0$ $\mathrm{Hz}, \mathrm{Ar}-\mathrm{H}), 7.24-7.28(1 \mathrm{H}, \mathrm{m}, \mathrm{Ar}-\mathrm{H}), 7.36-7.41$ (2H, m, Ar-H), 7.44-7.42 (2H, m, Ar-H), $7.60(1 \mathrm{H}, \mathrm{d}, J=12.0 \mathrm{~Hz}, \mathrm{Ar}-\mathrm{H}), 8.01-$ $8.04(2 \mathrm{H}, \mathrm{m}, \mathrm{Ar}-\mathrm{H})$. ESI-MS m/z: $528[\mathrm{M}+\mathrm{Na}]^{+}$.

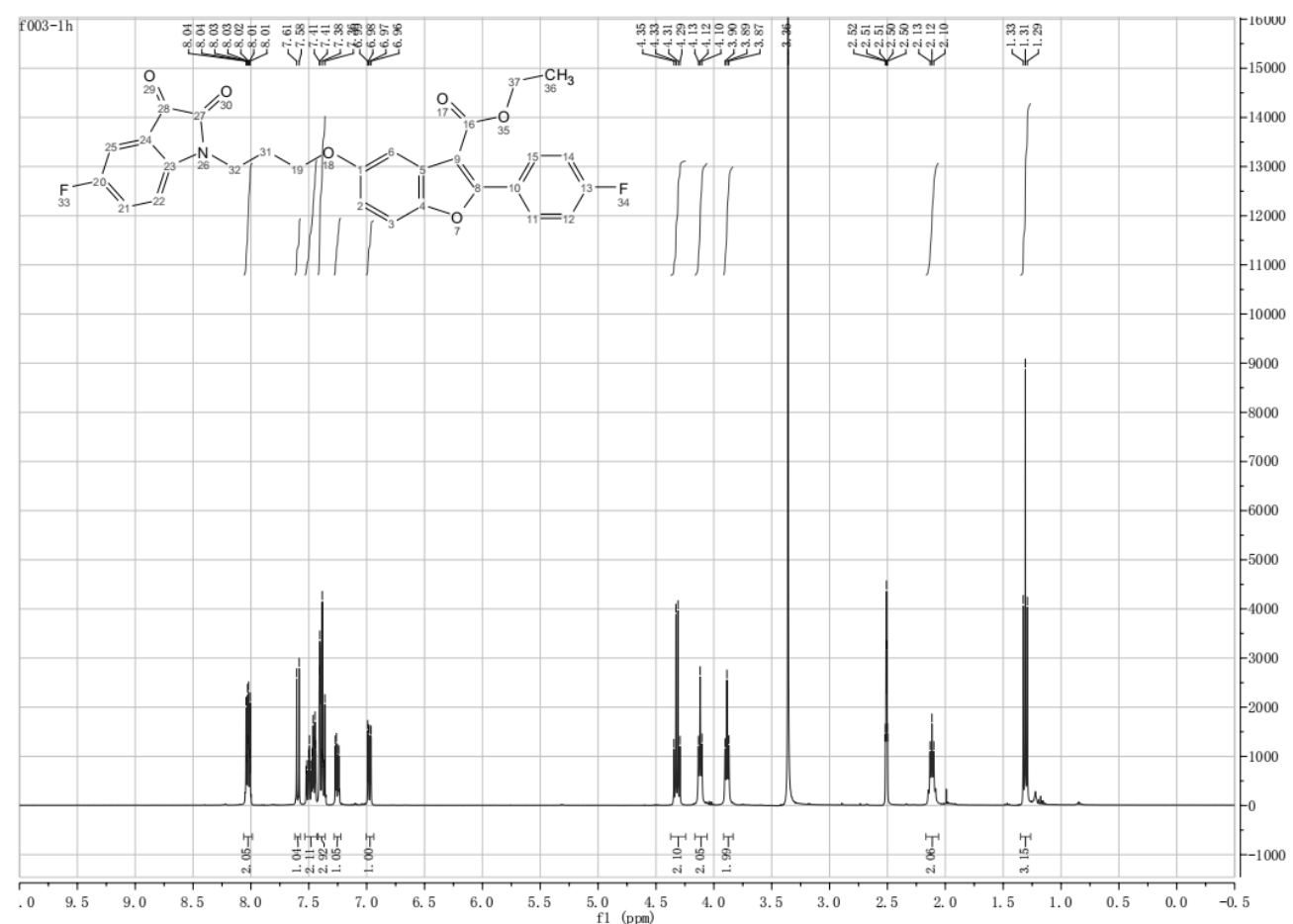


5-((5-(5-fluoro-2,3-dioxoindolin-1-yl)pentyl)oxy)-2-(4-methoxyphenyl)benzofuran-3-carboxylate (6c)

Yellow solid, yield: $58 \% .{ }^{1} \mathrm{H}$ NMR $\left(400 \mathrm{MHz}, \mathrm{DMSO}-d_{6}\right) \delta$

$1.32\left(3 \mathrm{H}, \mathrm{t}, J=8.0 \mathrm{~Hz}, \mathrm{CO}_{2} \mathrm{CH}_{2} \mathrm{CH}_{3}\right), 1.51-1.54(2 \mathrm{H}, \mathrm{m}$,

$\left.-\mathrm{CH}_{2-}\right), 1.66-1.70\left(2 \mathrm{H}, \mathrm{m},-\mathrm{CH}_{2}-\right), 1.78-1.82\left(2 \mathrm{H}, \mathrm{m},-\mathrm{CH}_{2^{-}}\right)$,

$3.68\left(2 \mathrm{H}, \mathrm{t}, J=8.0 \mathrm{~Hz},-\mathrm{CH}_{2}-\right), 3.85\left(3 \mathrm{H}, \mathrm{s}, \mathrm{OCH}_{3}\right), 4.01(2 \mathrm{H}$, $\left.\mathrm{t}, J=8.0 \mathrm{~Hz},-\mathrm{CH}_{2}-\right), 4.32\left(2 \mathrm{H}, \mathrm{q}, J=4.0 \mathrm{~Hz}, \mathrm{CO}_{2} \mathrm{CH}_{2} \mathrm{CH}_{3}\right)$, $6.96(1 \mathrm{H}, \mathrm{dd}, J=4.0,8.0 \mathrm{~Hz}, \operatorname{Ar}-\mathrm{H}), 7.09(2 \mathrm{H}, \mathrm{d}, J=8.0 \mathrm{~Hz}$, Ar-H), 7.41-7.45 (2H, m, Ar-H), 7.49-7.57 (2H, m, Ar-H), $7.57(1 \mathrm{H}, \mathrm{d}, J=8.0 \mathrm{~Hz}, \mathrm{Ar}-\mathrm{H}), 7.94-7.97(2 \mathrm{H}, \mathrm{m}, \mathrm{Ar}-\mathrm{H})$. ESIMS m/z: $568[\mathrm{M}+\mathrm{Na}]^{+}$.

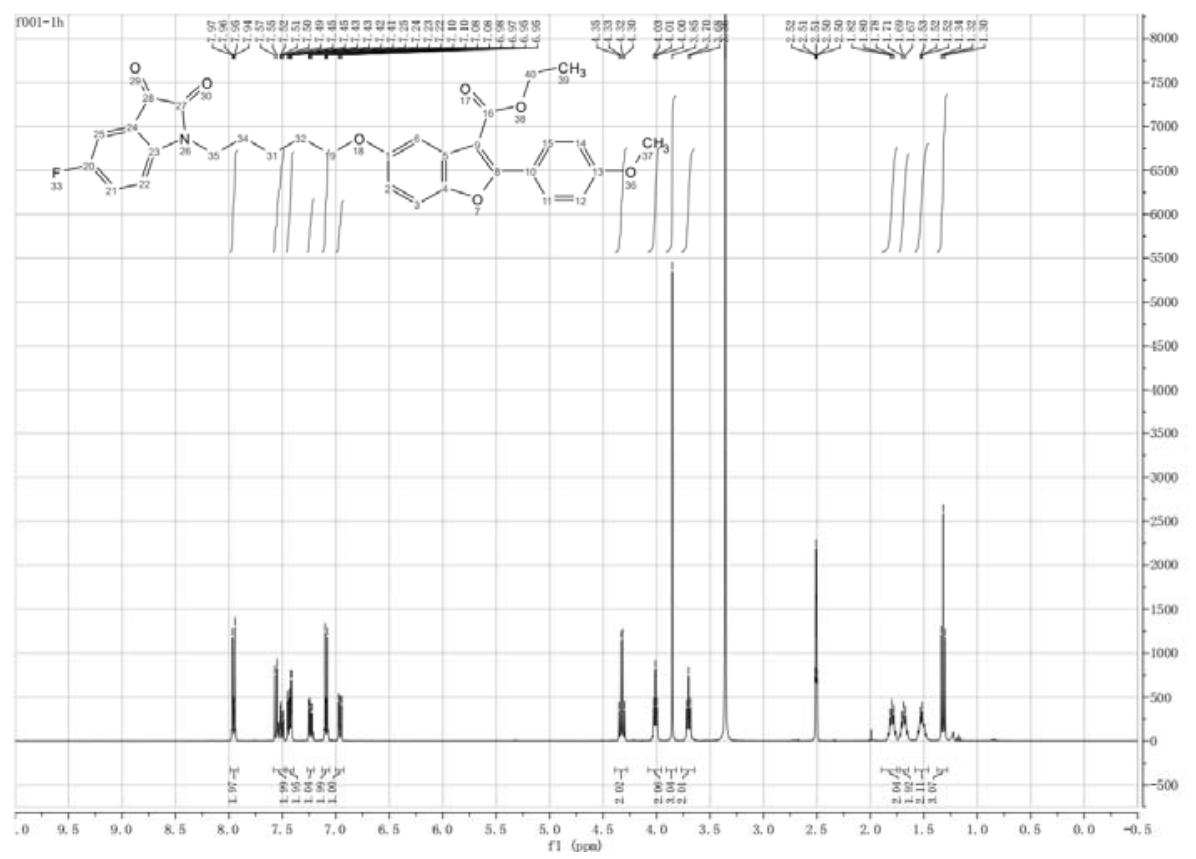

5-((6-(5-fluoro-2,3-dioxoindolin-1-yl)hexyl)oxy)-2-(4-methoxyphenyl)benzofuran-3-carboxylate (6d)

Yellow solid, yield: $62 \% .{ }^{1} \mathrm{H}$ NMR $\left(400 \mathrm{MHz}, \mathrm{DMSO}-d_{6}\right) \delta$ $1.32\left(3 \mathrm{H}, \mathrm{t}, J=8.0 \mathrm{~Hz}, \mathrm{CO}_{2} \mathrm{CH}_{2} \mathrm{CH}_{3}\right), 1.35-1.49(4 \mathrm{H}, \mathrm{m}, 2 \times-$ $\left.\mathrm{CH}_{2}-\right)$, 1.59-1.66 (2H, m, - $\left.\mathrm{CH}_{2-}\right), 1.70-1.77\left(2 \mathrm{H}, \mathrm{m},-\mathrm{CH}_{2}-\right)$, $3.66\left(2 \mathrm{H}, \mathrm{t}, J=8.0 \mathrm{~Hz},-\mathrm{CH}_{2}-\right), 3.85\left(3 \mathrm{H}, \mathrm{s}, \mathrm{OCH}_{3}\right), 4.00(2 \mathrm{H}$, $\left.\mathrm{t}, J=8.0 \mathrm{~Hz},-\mathrm{CH}_{2}-\right), 4.32\left(2 \mathrm{H}, \mathrm{q}, J=8.0 \mathrm{~Hz}, \mathrm{CO}_{2} \mathrm{CH}_{2} \mathrm{CH}_{3}\right)$, $6.94(1 \mathrm{H}, \mathrm{dd}, J=4.0,8.0 \mathrm{~Hz}, \mathrm{Ar}-\mathrm{H}), 7.07(2 \mathrm{H}, \mathrm{d}, J=8.0 \mathrm{~Hz}$, Ar-H), 7.19-7.22 (1H, m, Ar-H), 7.40-7.43 (2H, m, Ar-H), 7.49-7.54 (2H, m, Ar-H), 7.93-7.96 (2H, m, Ar-H). ESI-MS $\mathrm{m} / \mathrm{z}: 582[\mathrm{M}+\mathrm{Na}]^{+}$.

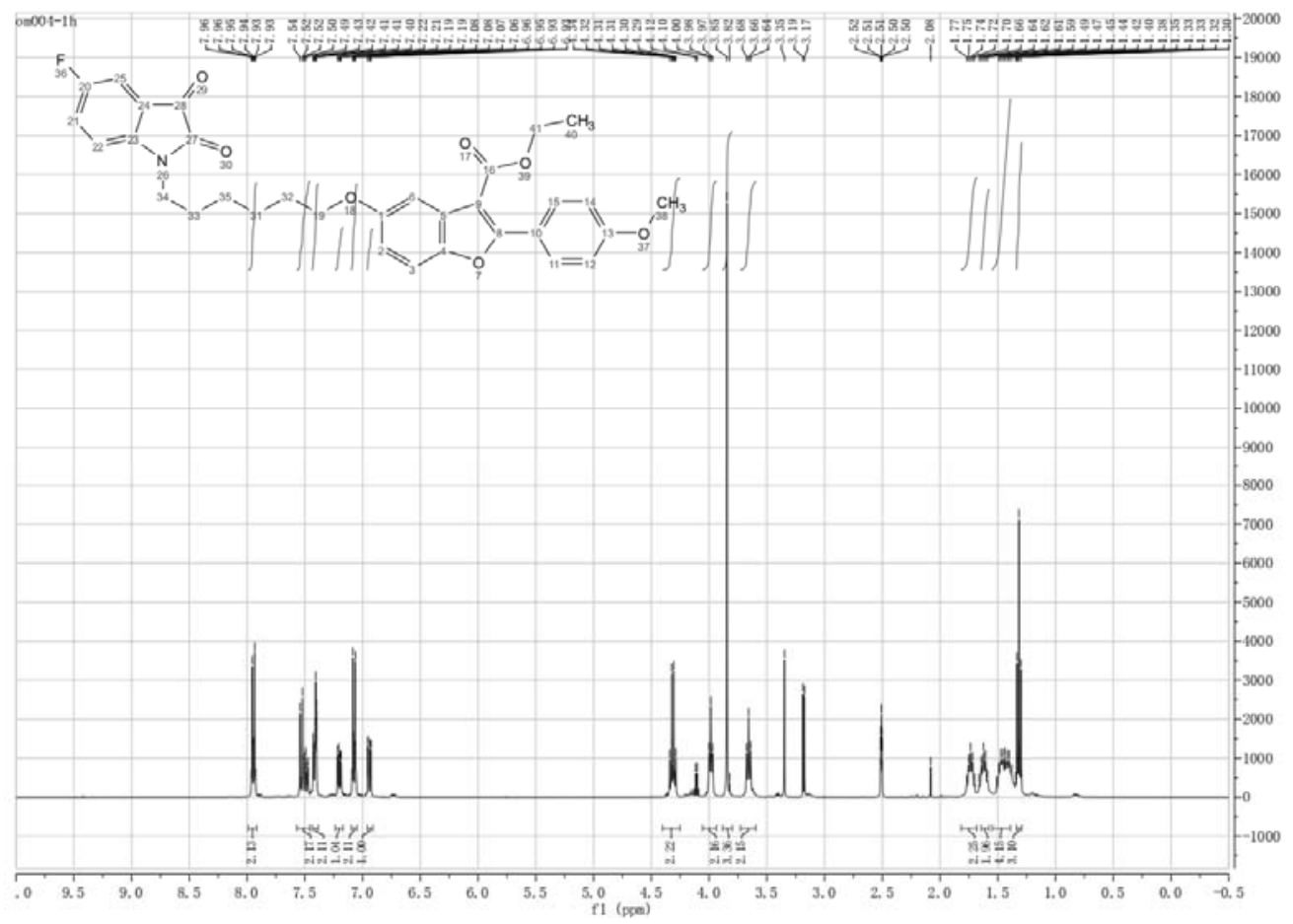


Ethyl ethyl 5-((6-(5-fluoro-2,3-dioxoindolin-1-yl)hexyl)oxy)-2(4-fluorophenyl)benzofuran-3-carboxylate (6e)

Yellow solid, yield: $62 \%$. ${ }^{1} \mathrm{H}$ NMR $\left(400 \mathrm{MHz}, \mathrm{DMSO}-d_{6}\right) \delta$

$1.31\left(3 \mathrm{H}, \mathrm{t}, J=8.0 \mathrm{~Hz}, \mathrm{CO}_{2} \mathrm{CH}_{2} \mathrm{CH}_{3}\right), 1.39-1.51(4 \mathrm{H}, \mathrm{m}, 2 \times-$

$\left.\mathrm{CH}_{2^{-}}\right), 1.62-1.65\left(2 \mathrm{H}, \mathrm{m},-\mathrm{CH}_{2^{-}}\right), 1.73-1.77\left(2 \mathrm{H}, \mathrm{m},-\mathrm{CH}_{2^{-}}\right)$, $3.68\left(2 \mathrm{H}, \mathrm{t}, J=4.0 \mathrm{~Hz},-\mathrm{CH}_{2}-\right), 4.03\left(2 \mathrm{H}, \mathrm{t}, J=4.0 \mathrm{~Hz},-\mathrm{CH}_{2}-\right.$ ), $4.32\left(2 \mathrm{H}, \mathrm{q}, J=8.0 \mathrm{~Hz}, \mathrm{CO}_{2} \mathrm{CH}_{2} \mathrm{CH}_{3}\right), 7.00(1 \mathrm{H}, \mathrm{dd}, J=4.0$, $8.0 \mathrm{~Hz}, \mathrm{Ar}-\mathrm{H}), 7.21-7.24(2 \mathrm{H}, \mathrm{m}, \mathrm{Ar}-\mathrm{H}), 7.36-7.54(5 \mathrm{H}, \mathrm{m}$, Ar-H), $7.58(1 \mathrm{H}, \mathrm{d}, J=8.0 \mathrm{~Hz}, \mathrm{Ar}-\mathrm{H}), 8.01-8.05$ (2H, m, ArH). ESI-MS m/z: $570[\mathrm{M}+\mathrm{Na}]^{+}$.

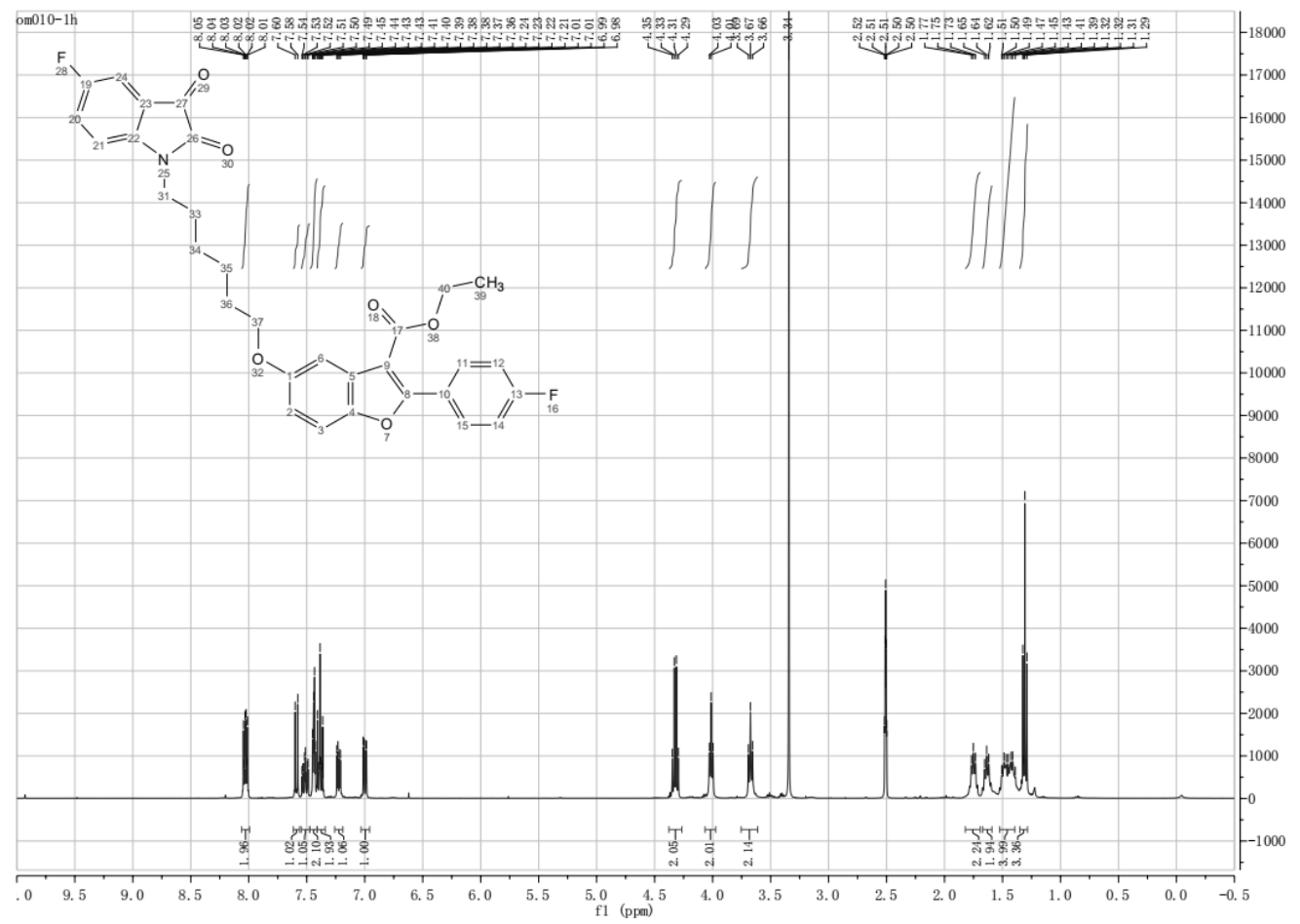

5-(3-(5-methoxy-2,3-dioxoindolin-1-yl)propoxy)-2-phenylbenzofuran-3-carboxylate (6f)

Yellow solid, yield: $59 \% .{ }^{1} \mathrm{H}$ NMR $\left(400 \mathrm{MHz}, \mathrm{DMSO}-d_{6}\right) \delta$ $1.42\left(3 \mathrm{H}, \mathrm{t}, J=8.0 \mathrm{~Hz}, \mathrm{CO}_{2} \mathrm{CH}_{2} \mathrm{CH}_{3}\right), 2.24-2.27(2 \mathrm{H}, \mathrm{m}$, $\left.-\mathrm{CH}_{2}-\right), 3.85\left(3 \mathrm{H}, \mathrm{s}, \mathrm{OCH}_{3}\right), 4.00\left(2 \mathrm{H}, \mathrm{t}, J=8.0 \mathrm{~Hz},-\mathrm{CH}_{2}-\right)$, $4.13\left(2 \mathrm{H}, \mathrm{t}, J=8.0 \mathrm{~Hz},-\mathrm{CH}_{2}-\right), 4.42(2 \mathrm{H}, \mathrm{q}, J=8.0 \mathrm{~Hz}$, $\left.\mathrm{CO}_{2} \mathrm{CH}_{2} \mathrm{CH}_{3}\right), 6.90(1 \mathrm{H}, \mathrm{dd}, J=4.0,8.0 \mathrm{~Hz}, \mathrm{Ar}-\mathrm{H}), 6.99-7.02$ $(3 \mathrm{H}, \mathrm{m}, \mathrm{Ar}-\mathrm{H}), 7.07-7.11(1 \mathrm{H}, \mathrm{m}, \mathrm{Ar}-\mathrm{H}), 7.38(1 \mathrm{H}, \mathrm{d}, J=12.0$ $\mathrm{Hz}, \mathrm{Ar}-\mathrm{H}), 7.50-7.55(2 \mathrm{H}, \mathrm{m}, \mathrm{Ar}-\mathrm{H}), 7.59-7.61(1 \mathrm{H}, \mathrm{m}, \mathrm{Ar}-\mathrm{H})$, 8.00-8.02 (2H, m, Ar-H). ESI-MS m/z: $522[\mathrm{M}+\mathrm{Na}]^{+}$.

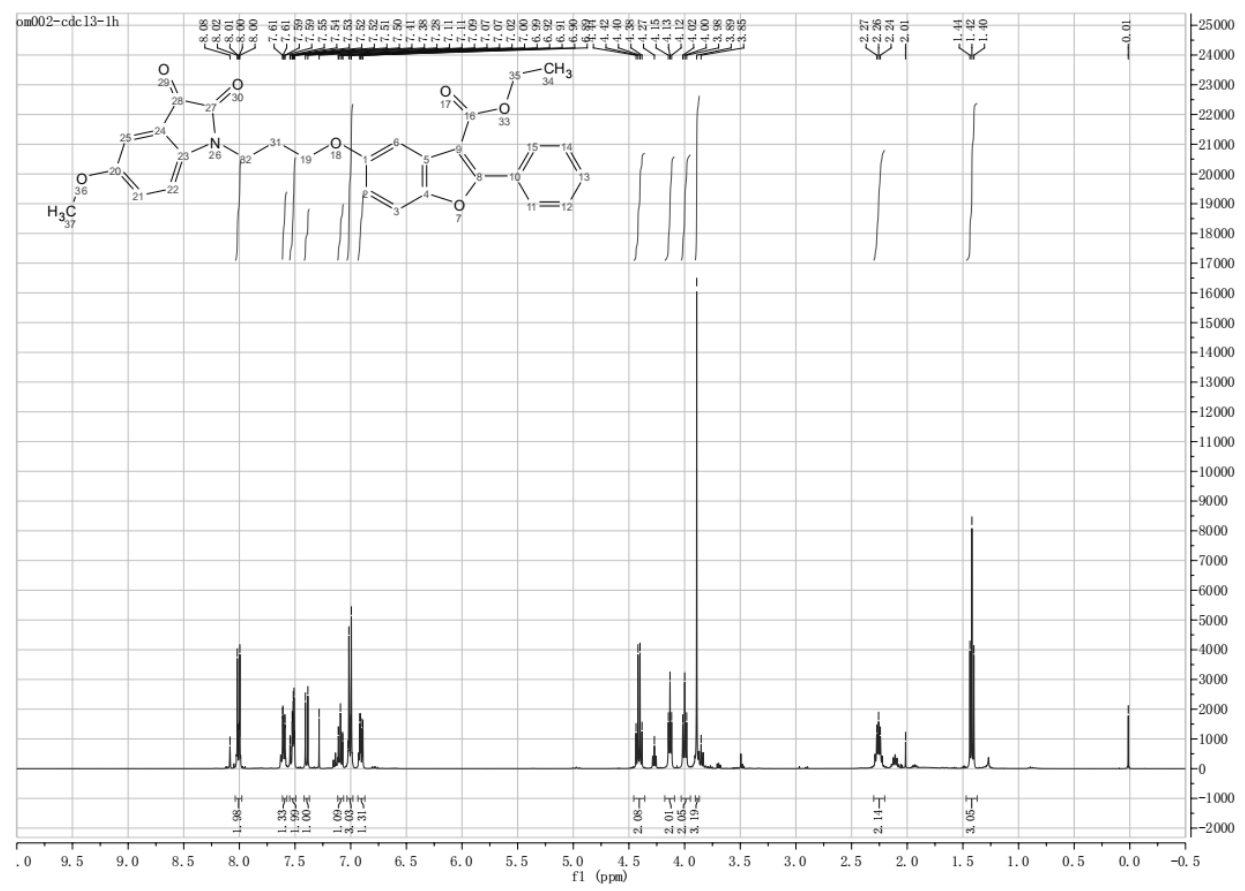


5-((5-(5-fluoro-2,3-dioxoindolin-1-yl)pentyl)oxy)-2-(4-methoxyphenyl)benzofuran-3-carboxylate $(\mathbf{6 g})$

Yellow solid, yield: $76 \%$. ${ }^{1} \mathrm{H}$ NMR $\left(400 \mathrm{MHz}, \mathrm{DMSO}-d_{6}\right) \delta$

$1.31\left(3 \mathrm{H}, \mathrm{t}, J=8.0 \mathrm{~Hz}, \mathrm{CO}_{2} \mathrm{CH}_{2} \mathrm{CH}_{3}\right), 2.12(2 \mathrm{H}, \mathrm{t}, J=4.0 \mathrm{~Hz}$, $\left.-\mathrm{CH}_{2}-\right), 3.76\left(3 \mathrm{H}, \mathrm{s}, \mathrm{OCH}_{3}\right), 3.87\left(2 \mathrm{H}, \mathrm{t}, J=4.0 \mathrm{~Hz},-\mathrm{CH}_{2^{-}}\right)$, $4.12\left(2 \mathrm{H}, \mathrm{t}, J=2.0 \mathrm{~Hz},-\mathrm{CH}_{2}-\right), 4.32(2 \mathrm{H}, \mathrm{q}, J=8.0 \mathrm{~Hz}$, $\left.\mathrm{CO}_{2} \mathrm{CH}_{2} \mathrm{CH}_{3}\right), 6.98(1 \mathrm{H}, \mathrm{dd}, J=4.0,8.0 \mathrm{~Hz}, \mathrm{Ar}-\mathrm{H}), 7.14-7.20$ $(3 \mathrm{H}, \mathrm{m}, \mathrm{Ar}-\mathrm{H}), 7.37-7.42(3 \mathrm{H}, \mathrm{m}, \mathrm{Ar}-\mathrm{H}), 7.60(1 \mathrm{H}, \mathrm{d}$, $J=12.0 \mathrm{~Hz}$, Ar-H), 8.01-8.05 (2H, m, Ar-H). ESI-MS m/z: $540[\mathrm{M}+\mathrm{Na}]^{+}$.

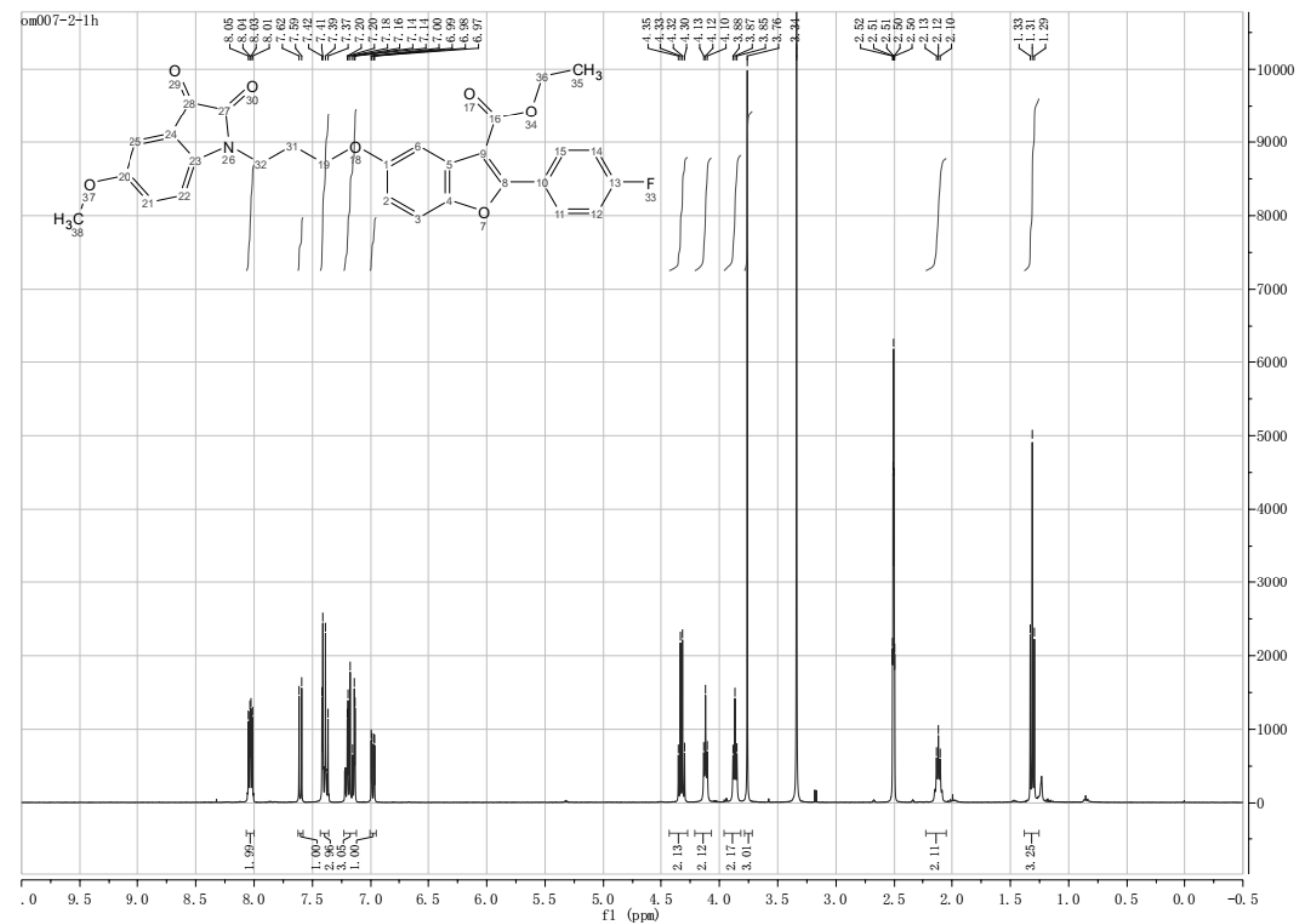

5-(4-(5-methoxy-2,3-dioxoindolin-1-yl)butoxy)-2-(4-methoxyphenyl)benzofuran-3-carboxylate $(\mathbf{6 h})$

Yellow solid, yield: $62 \% .{ }^{1} \mathrm{H}$ NMR $\left(400 \mathrm{MHz}, \mathrm{DMSO}-d_{6}\right) \delta$ $1.32\left(3 \mathrm{H}, \mathrm{t}, J=8.0 \mathrm{~Hz}, \mathrm{CO}_{2} \mathrm{CH}_{2} \mathrm{CH}_{3}\right), 1.80-1.84(4 \mathrm{H}, \mathrm{m}, 2 \times-$ $\left.\mathrm{CH}_{2}-\right), 3.71-3.76\left(5 \mathrm{H}, \mathrm{m},-\mathrm{CH}_{2^{-}}\right.$and $\left.\mathrm{OCH}_{3}\right), 3.85(3 \mathrm{H}, \mathrm{s}$,
$\left.\mathrm{OCH}_{3}\right), 4.06\left(2 \mathrm{H}, \mathrm{t}, J=8.0 \mathrm{~Hz},-\mathrm{CH}_{2}-\right), 4.33(2 \mathrm{H}, \mathrm{q}, J=8.0$ $\left.\mathrm{Hz}, \mathrm{CO}_{2} \mathrm{CH}_{2} \mathrm{CH}_{3}\right), 6.96(1 \mathrm{H}, \mathrm{dd}, J=4.0,8.0 \mathrm{~Hz}, \mathrm{Ar}-\mathrm{H}), 7.08-$ $7.16(4 \mathrm{H}, \mathrm{m}, \mathrm{Ar}-\mathrm{H}), 7.22-7.25(1 \mathrm{H}, \mathrm{m}, \mathrm{Ar}-\mathrm{H}), 7.42(1 \mathrm{H}, \mathrm{d}$, $J=4.0 \mathrm{~Hz}, \mathrm{Ar}-\mathrm{H}), 7.55(1 \mathrm{H}, \mathrm{d}, J=8.0 \mathrm{~Hz}, \mathrm{Ar}-\mathrm{H}), 7.94-7.97$ $(2 \mathrm{H}, \mathrm{m}, \mathrm{Ar}-\mathrm{H})$. ESI-MS m/z: $566[\mathrm{M}+\mathrm{Na}]^{+}$.

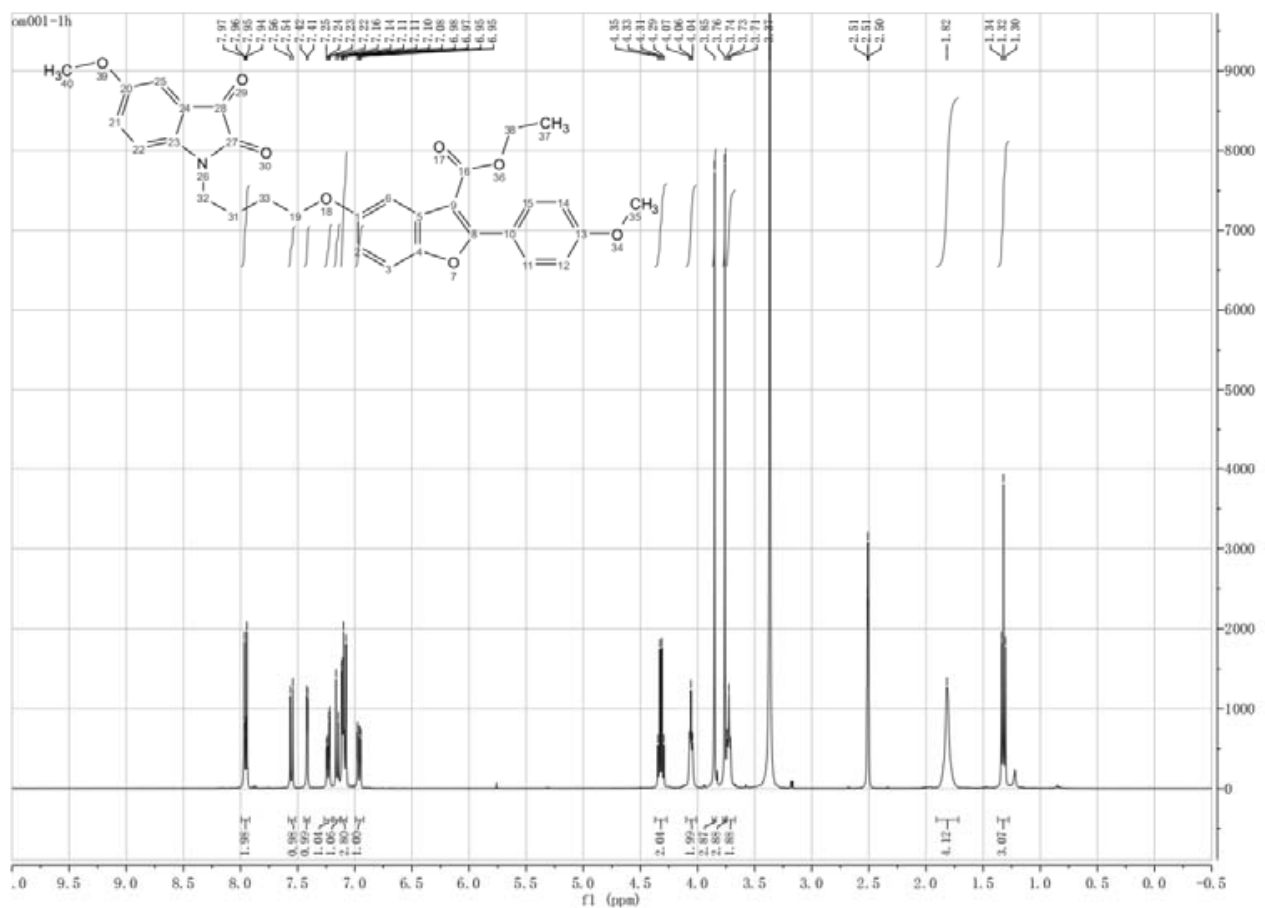


2-(4-fluorophenyl)-5-((5-(5-methoxy-2,3-dioxoindolin-1-yl)pentyl) oxy)benzofuran-3-carboxylate (6i)

Yellow solid, yield: $66 \%$. ${ }^{1} \mathrm{H}$ NMR $\left(400 \mathrm{MHz}, \mathrm{DMSO}-d_{6}\right) \delta$ $1.32\left(3 \mathrm{H}, \mathrm{t}, J=8.0 \mathrm{~Hz}, \mathrm{CO}_{2} \mathrm{CH}_{2} \mathrm{CH}_{3}\right), 1.50-1.55(2 \mathrm{H}, \mathrm{m}$, $\left.-\mathrm{CH}_{2}-\right), 1.65-1.71\left(2 \mathrm{H}, \mathrm{m},-\mathrm{CH}_{2}-\right), 1.76-1.82\left(2 \mathrm{H}, \mathrm{m},-\mathrm{CH}_{2}-\right)$, $4.68\left(2 \mathrm{H}, \mathrm{t}, J=8.0 \mathrm{~Hz},-\mathrm{CH}_{2}-\right), 3.85\left(3 \mathrm{H}, \mathrm{s}, \mathrm{OCH}_{3}\right), 4.01(2 \mathrm{H}$, t, $\left.J=8.0 \mathrm{~Hz},-\mathrm{CH}_{2}-\right), 4.32\left(2 \mathrm{H}, \mathrm{q}, J=8.0 \mathrm{~Hz}, \mathrm{CO}_{2} \mathrm{CH}_{2} \mathrm{CH}_{3}\right)$, $6.96(1 \mathrm{H}, \mathrm{dd}, J=4.0,8.0 \mathrm{~Hz}, \mathrm{Ar}-\mathrm{H}), 7.08-7.11(2 \mathrm{H}, \mathrm{m}, \mathrm{Ar}-\mathrm{H})$, 7.22-7.25 (1H, m, Ar-H), 7.41-7.45 (2H, m, Ar-H), 7.49-7.57 $(2 \mathrm{H}, \mathrm{m}, \mathrm{Ar}-\mathrm{H}), 7.94-7.97$ (2H, m, Ar-H). ESI-MS m/z: 568 $[\mathrm{M}+\mathrm{Na}]^{+}$.

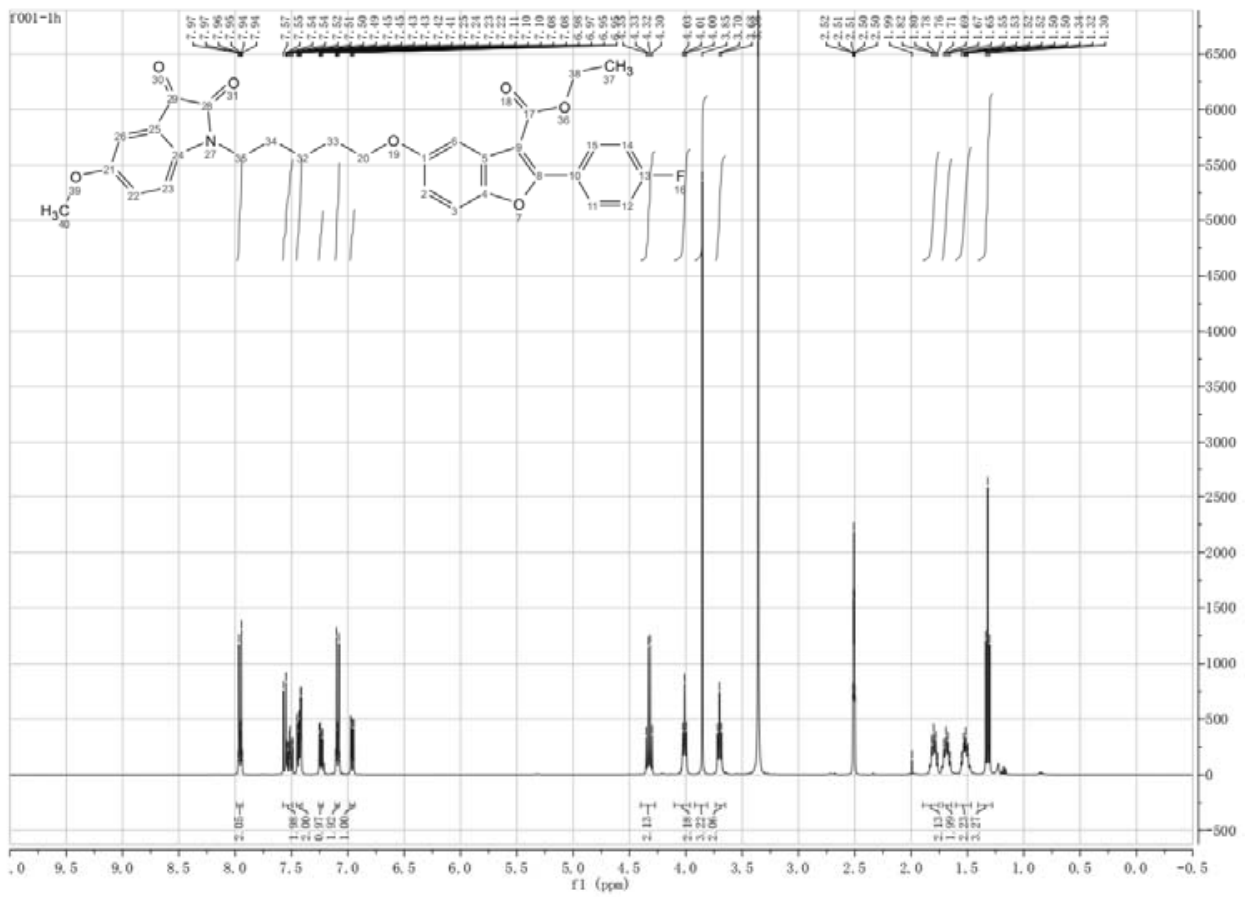

5-(3-(2,3-dioxoindolin-1-yl)propoxy)-2-(4-fluorophenyl)benzofuran-3-carboxylate $(\mathbf{6 j})$

Yellow solid, yield: $83 \%$. ${ }^{1} \mathrm{H}$ NMR $\left(400 \mathrm{MHz}, \mathrm{DMSO}-d_{6}\right) \delta$ $1.31\left(3 \mathrm{H}, \mathrm{t}, J=8.0 \mathrm{~Hz}, \mathrm{CO}_{2} \mathrm{CH}_{2} \mathrm{CH}_{3}\right), 2.13(2 \mathrm{H}, \mathrm{t}, J=8.0 \mathrm{~Hz}$, $\left.-\mathrm{CH}_{2}-\right), 3.89\left(2 \mathrm{H}, \mathrm{t}, J=4.0 \mathrm{~Hz},-\mathrm{CH}_{2}-\right), 4.12(2 \mathrm{H}, \mathrm{t}, J=4.0$
$\left.\mathrm{Hz},-\mathrm{CH}_{2}-\right), 4.33\left(2 \mathrm{H}, \mathrm{q}, J=8.0 \mathrm{~Hz}, \mathrm{CO}_{2} \mathrm{CH}_{2} \mathrm{CH}_{3}\right), 6.98(1 \mathrm{H}$, $\mathrm{dd}, J=4.0,8.0 \mathrm{~Hz}, \mathrm{Ar}-\mathrm{H}), 7.11(1 \mathrm{H}, \mathrm{t}, J=4.0 \mathrm{~Hz}, \mathrm{Ar}-\mathrm{H}), 7.24$ $(1 \mathrm{H}, \mathrm{d}, J=8.0 \mathrm{~Hz}, \mathrm{Ar}-\mathrm{H}), 7.37-7.42(3 \mathrm{H}, \mathrm{m}, \mathrm{Ar}-\mathrm{H}), 7.54-7.64$ $(3 \mathrm{H}, \mathrm{m}, \mathrm{Ar}-\mathrm{H}), 8.01-8.05(2 \mathrm{H}, \mathrm{d}, J=8.0 \mathrm{~Hz}, \mathrm{Ar}-\mathrm{H})$. ESI-MS $\mathrm{m} / \mathrm{z}: 510[\mathrm{M}+\mathrm{Na}]^{+}$.

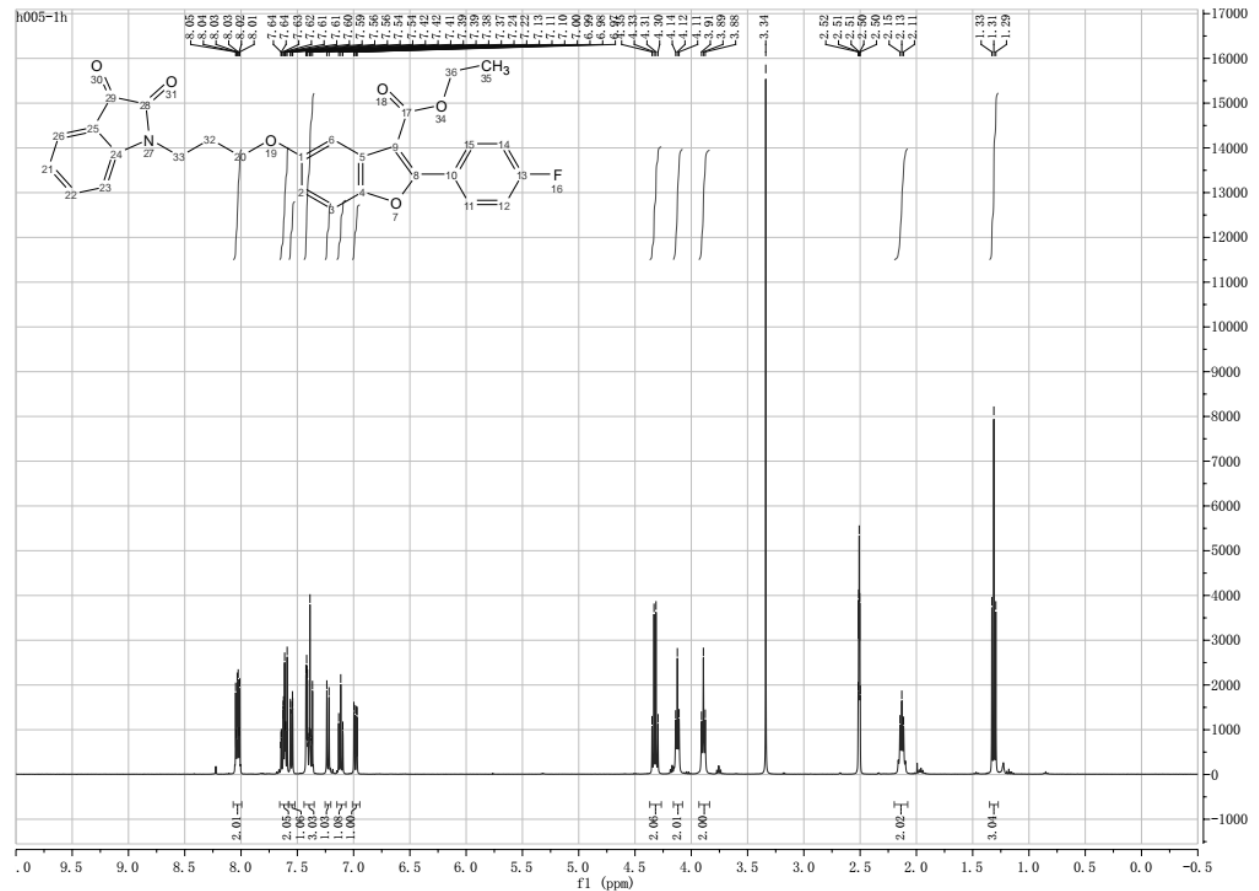


5-(3-(2,3-dioxoindolin-1-yl)propoxy)-2-(4-methoxyphenyl) benzofuran-3-carboxylate (6k)

Yellow solid, yield: $77 \%$. ${ }^{1} \mathrm{H}$ NMR (400 MHz, DMSO- $\left.d_{6}\right) \delta$

$1.33\left(3 \mathrm{H}, \mathrm{t}, J=4.0 \mathrm{~Hz}, \mathrm{CO}_{2} \mathrm{CH}_{2} \mathrm{CH}_{3}\right), 2.13(2 \mathrm{H}, \mathrm{t}, J=4.0 \mathrm{~Hz}$, $\left.-\mathrm{CH}_{2}-\right), 3.86\left(3 \mathrm{H}, \mathrm{s}, \mathrm{OCH}_{3}\right), 3.88\left(2 \mathrm{H}, \mathrm{t}, J=4.0 \mathrm{~Hz},-\mathrm{CH}_{2^{-}}\right)$, $4.12\left(2 \mathrm{H}, \mathrm{t}, J=4.0 \mathrm{~Hz},-\mathrm{CH}_{2}-\right), 4.34(2 \mathrm{H}, \mathrm{q}, J=4.0 \mathrm{~Hz}$, $\left.\mathrm{CO}_{2} \mathrm{CH}_{2} \mathrm{CH}_{3}\right), 6.96(1 \mathrm{H}, \mathrm{dd}, J=4.0,8.0 \mathrm{~Hz}, \mathrm{Ar}-\mathrm{H}), 7.08-7.13$ $(3 \mathrm{H}, \mathrm{m}, \mathrm{Ar}-\mathrm{H}), 7.24(1 \mathrm{H}, \mathrm{d}, J=8.0 \mathrm{~Hz}, \mathrm{Ar}-\mathrm{H}), 7.40(1 \mathrm{H}, \mathrm{d}$, $J=8.0 \mathrm{~Hz}, \mathrm{Ar}-\mathrm{H}), 7.54-7.63(3 \mathrm{H}, \mathrm{m}, \mathrm{Ar}-\mathrm{H}), 7.96(2 \mathrm{H}, \mathrm{d}, J=$ $8.0 \mathrm{~Hz}, \mathrm{Ar}-\mathrm{H})$. ESI-MS m/z: $522[\mathrm{M}+\mathrm{Na}]^{+}$.

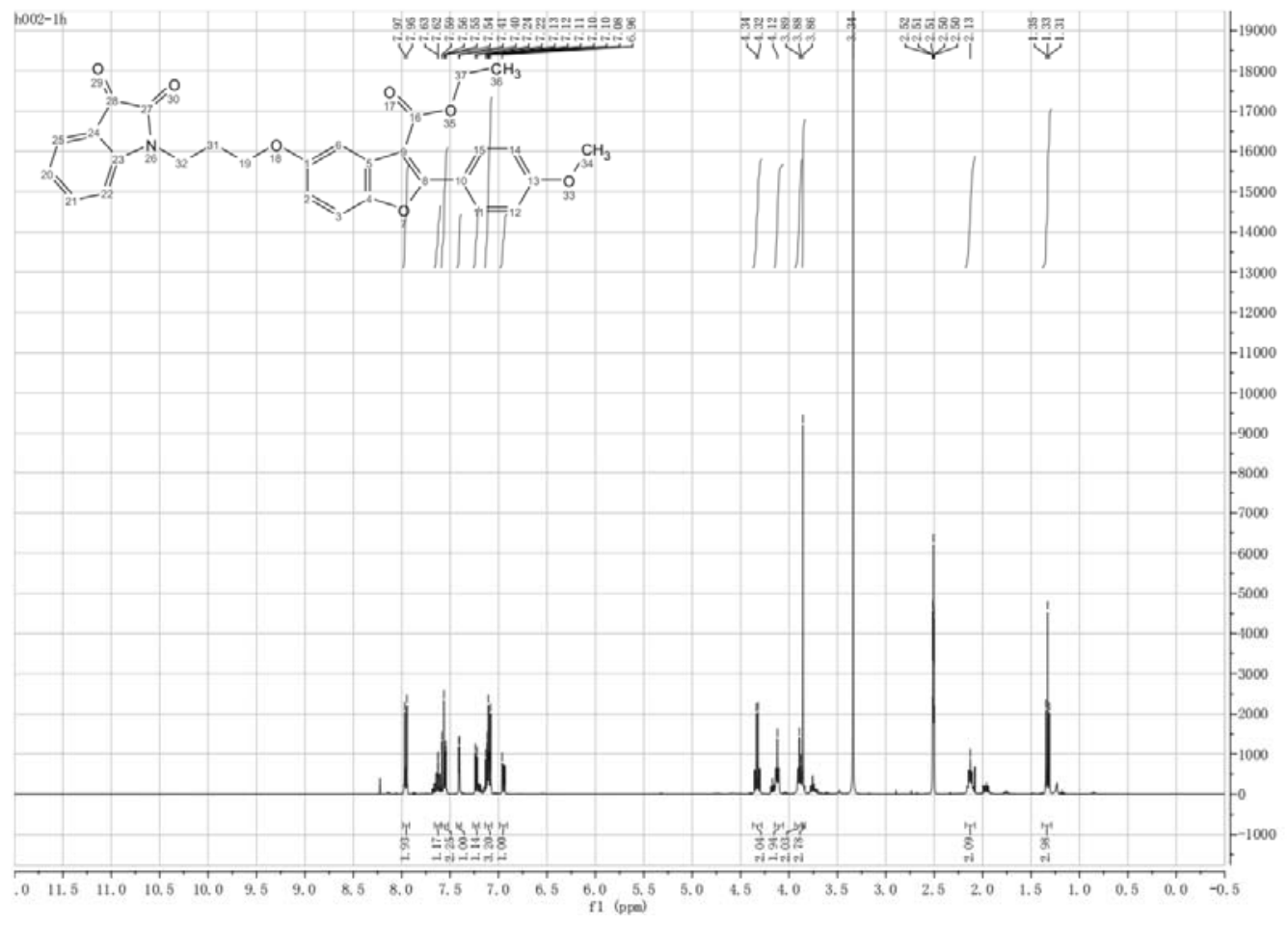

5-(4-(2,3-dioxoindolin-1-yl)butoxy)-2-(4-methoxyphenyl)benzofuran-3-carboxylate $\mathbf{( 6 \mathbf { 1 } )}$

Yellow solid, yield: $68 \%$. ${ }^{1} \mathrm{H}$ NMR $\left(400 \mathrm{MHz}, \mathrm{CDCl}_{3}\right) \delta 1.39$ $\left(3 \mathrm{H}, \mathrm{t}, J=8.0 \mathrm{~Hz}, \mathrm{CO}_{2} \mathrm{CH}_{2} \mathrm{CH}_{3}\right), 1.86-1.94\left(4 \mathrm{H}, \mathrm{m}, 2 \times-\mathrm{CH}_{2}-\right)$, $3.78\left(2 \mathrm{H}, \mathrm{t}, J=8.0 \mathrm{~Hz},-\mathrm{CH}_{2}-\right), 3.84\left(3 \mathrm{H}, \mathrm{s}, \mathrm{OCH}_{3}\right), 4.04(2 \mathrm{H}$, t, $\left.J=4.0 \mathrm{~Hz},-\mathrm{CH}_{2}-\right), 4.38\left(2 \mathrm{H}, \mathrm{q}, J=8.0 \mathrm{~Hz}, \mathrm{CO}_{2} \mathrm{CH}_{2} \mathrm{CH}_{3}\right)$, 6.85-6.91 (2H, m, Ar-H), 6.94-6.89 (2H, m, Ar-H), $7.06(1 \mathrm{H}$, $\mathrm{t}, J=8.0 \mathrm{~Hz}, \mathrm{Ar}-\mathrm{H}), 7.34(1 \mathrm{H}, \mathrm{d}, J=12.0 \mathrm{~Hz}, \mathrm{Ar}-\mathrm{H}), 7.48$ $(1 \mathrm{H}, \mathrm{d}, J=4.0 \mathrm{~Hz}, \mathrm{Ar}-\mathrm{H}), 7.50-7.53(1 \mathrm{H}, \mathrm{m}, \mathrm{Ar}-\mathrm{H}), 7.95-7.99$ $(2 \mathrm{H}, \mathrm{m}, \mathrm{Ar}-\mathrm{H})$. ESI-MS m/z: $536[\mathrm{M}+\mathrm{Na}]^{+}$.

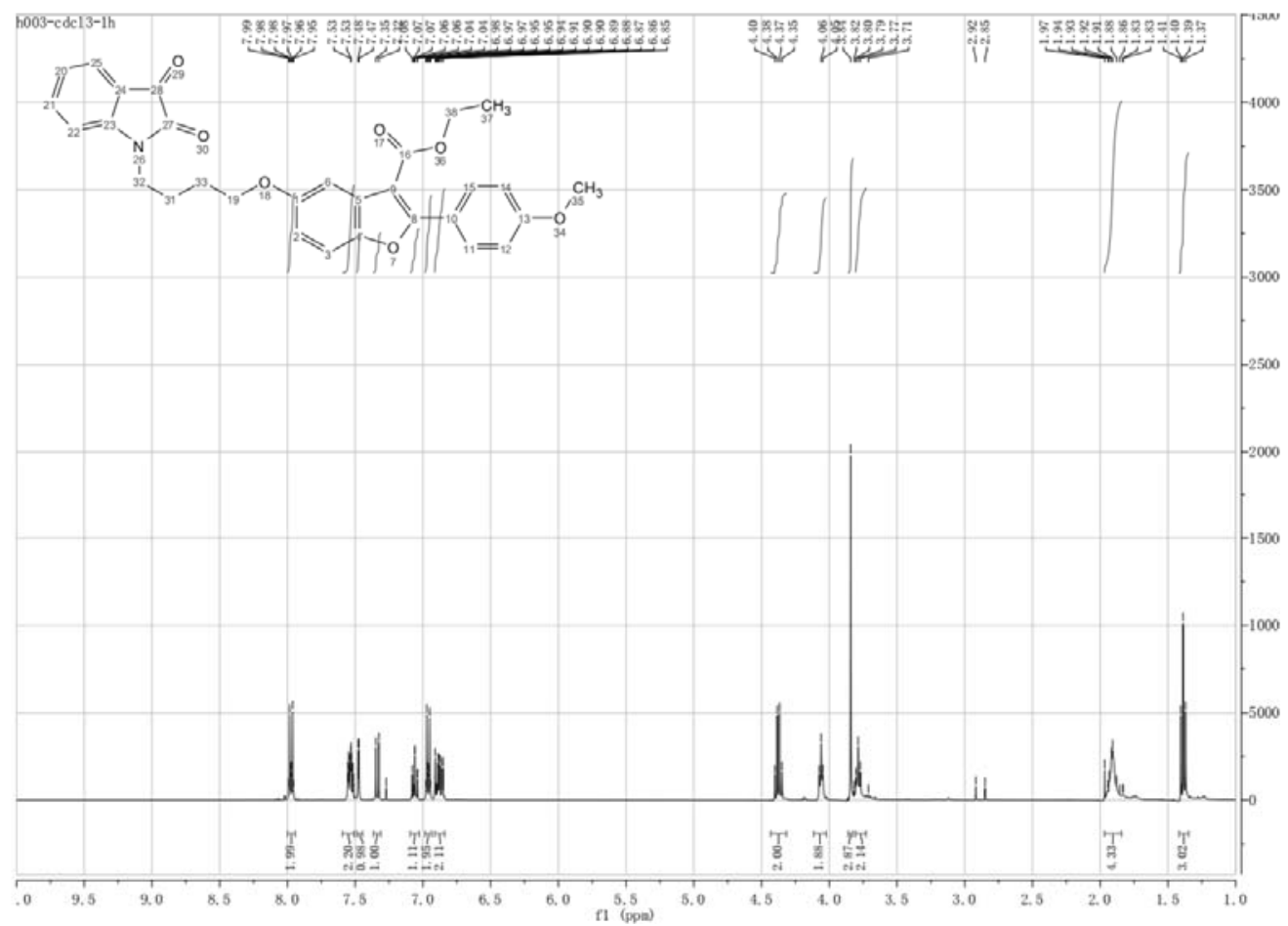


ethyl 5-((6-(2,3-dioxoindolin-1-yl)hexyl)oxy)-2-(4-methoxyphenyl)benzofuran-3-carboxylate $(\mathbf{6 m})$

Yellow solid, yield: 59\%. ${ }^{1} \mathrm{H}$ NMR $\left(400 \mathrm{MHz}, \mathrm{CDCl}_{3}\right) \delta 1.43$

$\left(3 \mathrm{H}, \mathrm{t}, J=8.0 \mathrm{~Hz}, \mathrm{CO}_{2} \mathrm{CH}_{2} \mathrm{CH}_{3}\right), 1.48-1.56\left(4 \mathrm{H}, \mathrm{m}, 2 \times-\mathrm{CH}_{2}-\right)$,

1.76-1.87 (4H, m, $\left.2 \times-\mathrm{CH}_{2}-\right), 3.76\left(2 \mathrm{H}, \mathrm{t}, J=8.0 \mathrm{~Hz},-\mathrm{CH}_{2}-\right)$, $3.88\left(3 \mathrm{H}, \mathrm{s}, \mathrm{OCH}_{3}\right), 4.05\left(2 \mathrm{H}, \mathrm{t}, J=8.0 \mathrm{~Hz},-\mathrm{CH}_{2}-\right), 4.43(2 \mathrm{H}$, q, $\left.J=8.0 \mathrm{~Hz}, \mathrm{CO}_{2} \mathrm{CH}_{2} \mathrm{CH}_{3}\right), 6.91-6.94(2 \mathrm{H}, \mathrm{m}, \mathrm{Ar}-\mathrm{H}), 7.02$ $(2 \mathrm{H}, \mathrm{d}, J=8.0 \mathrm{~Hz}, \mathrm{Ar}-\mathrm{H}), 7.12(1 \mathrm{H}, \mathrm{t}, J=4.0 \mathrm{~Hz}, \mathrm{Ar}-\mathrm{H}), 7.40$ $(1 \mathrm{H}, \mathrm{d}, J=8.0 \mathrm{~Hz}, \mathrm{Ar}-\mathrm{H}), 7.53(1 \mathrm{H}, \mathrm{d}, J=4.0 \mathrm{~Hz}, \mathrm{Ar}-\mathrm{H})$, 7.57-7.63 (2H, m, Ar-H), 7.99-8.02 (2H, m, Ar-H). ESI-MS $\mathrm{m} / \mathrm{z}: 565[\mathrm{M}+\mathrm{Na}]^{+}$.

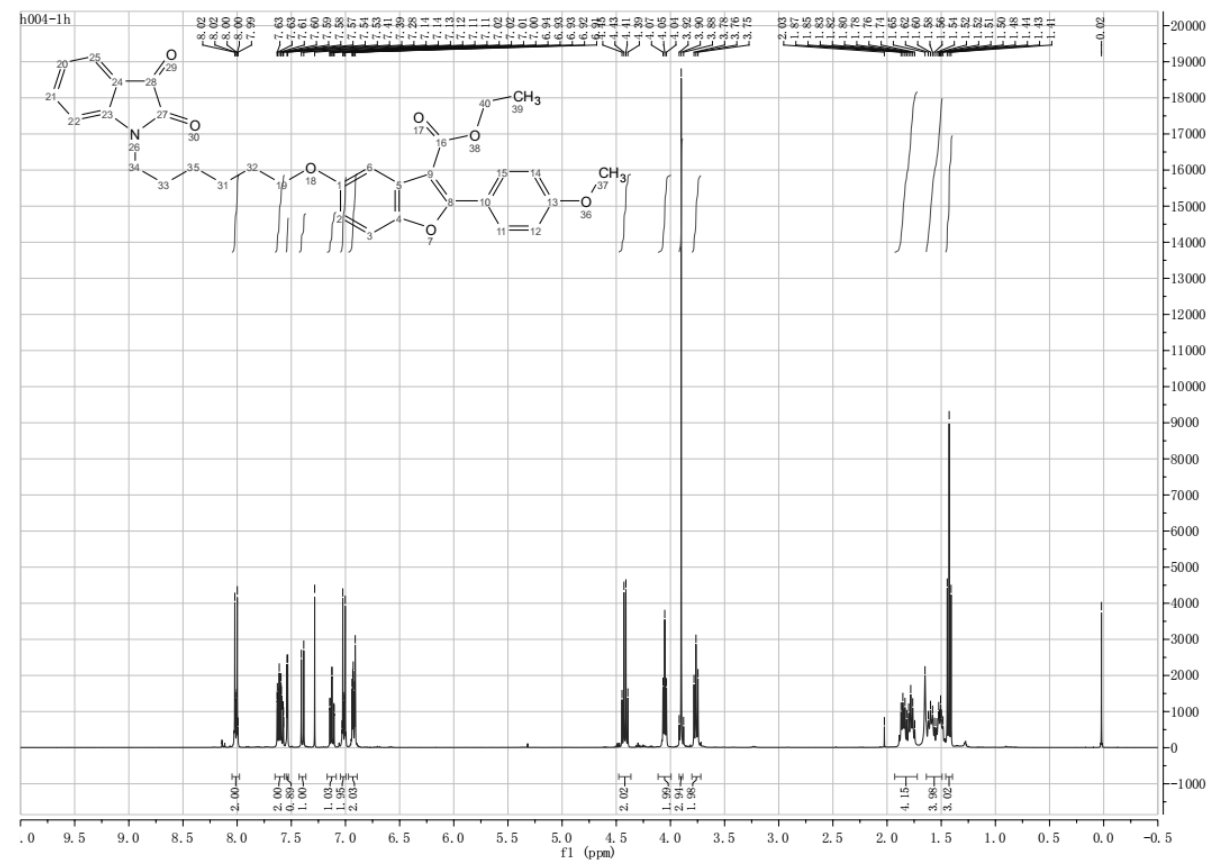

Ethyl 5-(3-(3-(hydroxyimino)-2-oxoindolin-1-yl)propoxy)-2(4-methoxyphenyl)benzofuran-3-carboxylate (61)

Yellow solid, yield: $51 \% .{ }^{1} \mathrm{H}$ NMR $\left(400 \mathrm{MHz}, \mathrm{DMSO}-d_{6}\right) \delta$ $1.32\left(3 \mathrm{H}, \mathrm{t}, J=8.0 \mathrm{~Hz}, \mathrm{CO}_{2} \mathrm{CH}_{2} \mathrm{CH}_{3}\right), 2.10(2 \mathrm{H}, \mathrm{t}, J=8.0 \mathrm{~Hz}$, $\left.-\mathrm{CH}_{2}-\right), 3.85\left(3 \mathrm{H}, \mathrm{s}, \mathrm{OCH}_{3}\right), 3.93\left(2 \mathrm{H}, \mathrm{t}, J=8.0 \mathrm{~Hz},-\mathrm{CH}_{2}-\right)$, $4.08\left(2 \mathrm{H}, \mathrm{t}, J=8.0 \mathrm{~Hz},-\mathrm{CH}_{2}-\right), 4.32(2 \mathrm{H}, \mathrm{q}, J=8.0 \mathrm{~Hz}$,
$\left.\mathrm{CO}_{2} \mathrm{CH}_{2} \mathrm{CH}_{3}\right), 6.93(1 \mathrm{H}, \mathrm{dd}, J=4.0,8.0 \mathrm{~Hz}, \mathrm{Ar}-\mathrm{H}), 7.07-7.10$ $(3 \mathrm{H}, \mathrm{m}, \mathrm{Ar}-\mathrm{H}), 7.16(1 \mathrm{H}, \mathrm{d}, J=8.0 \mathrm{~Hz}, \mathrm{Ar}-\mathrm{H}), 7.40-7.42(2 \mathrm{H}$, m, Ar-H), $7.56(1 \mathrm{H}, \mathrm{d}, J=8.0 \mathrm{~Hz}, \mathrm{Ar}-\mathrm{H}), 7.96(2 \mathrm{H}, \mathrm{d}, J=8.0$ $\mathrm{Hz}, \mathrm{Ar}-\mathrm{H}), 8.00(1 \mathrm{H}, \mathrm{d}, J=4.0 \mathrm{~Hz}, \mathrm{Ar}-\mathrm{H}), 13.41(1 \mathrm{H}, \mathrm{s}$, $\mathrm{NOH})$. ESI-MS m/z: $537[\mathrm{M}+\mathrm{Na}]^{+}$.

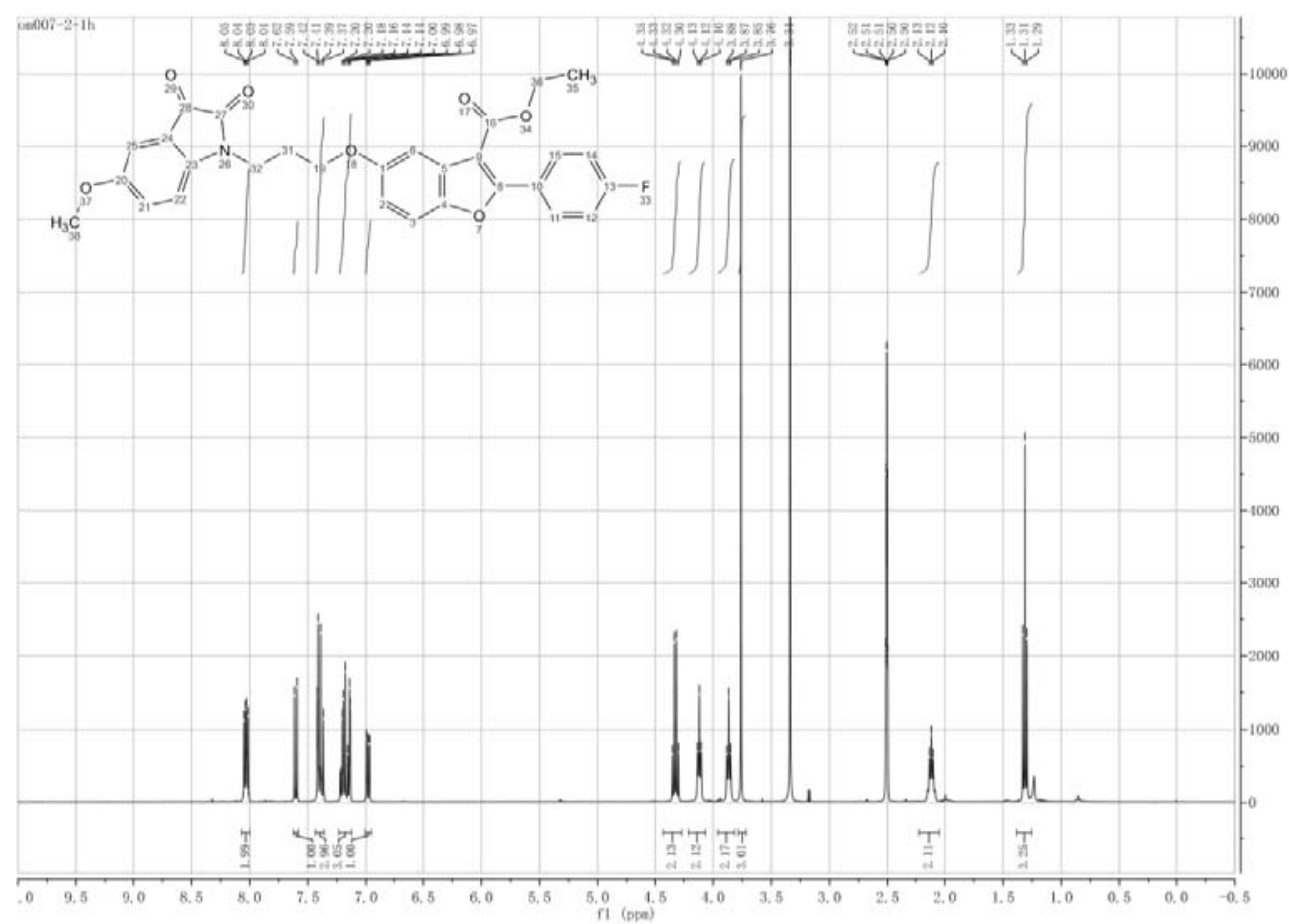



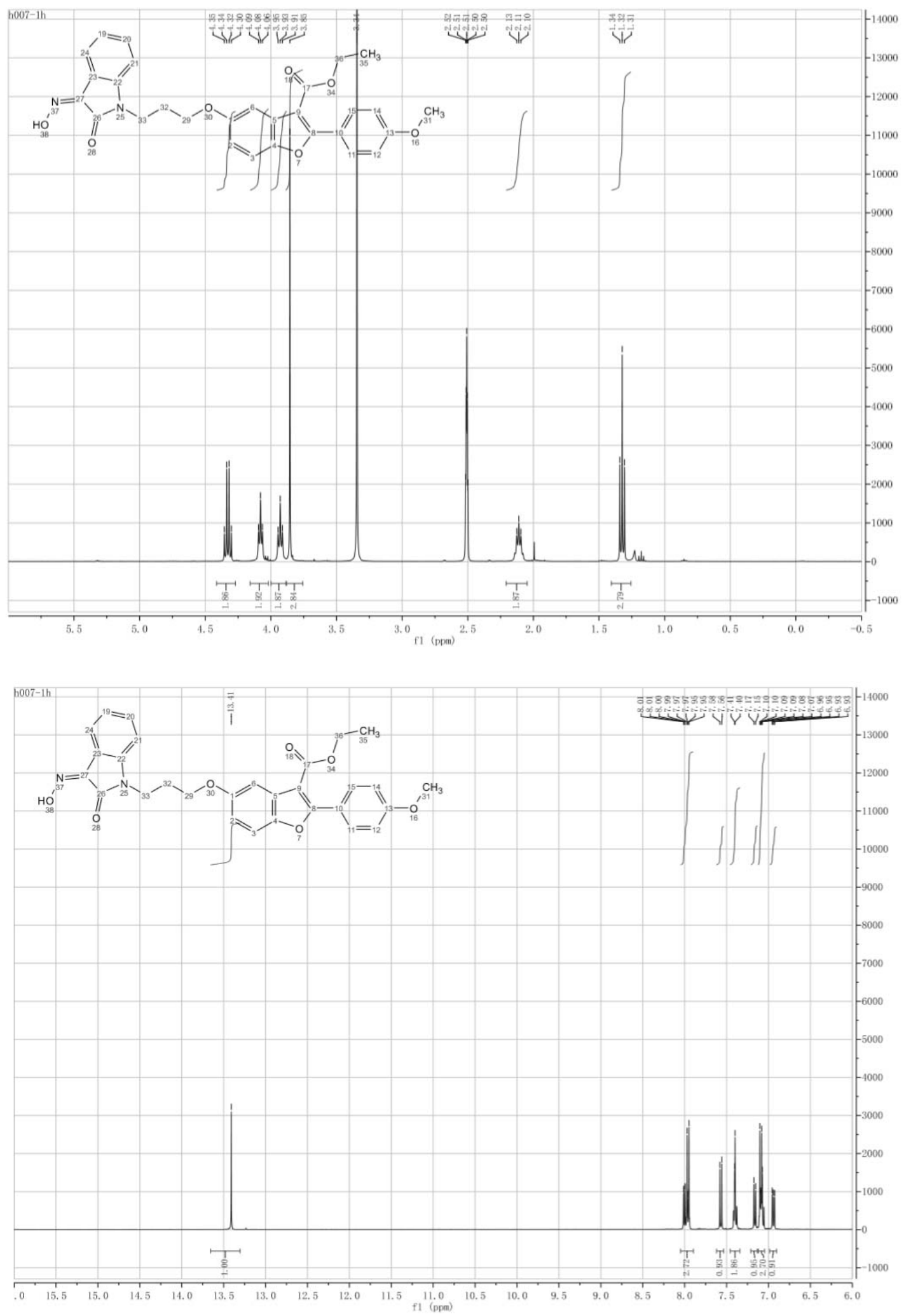

Ethyl 5-(4-(3-(hydroxyimino)-2-oxoindolin-1-yl)butoxy)-2-(4methoxyphenyl)benzofuran-3-carboxylate (6n)

Yellow solid, yield: $38 \% .{ }^{1} \mathrm{H}$ NMR $\left(400 \mathrm{MHz}, \mathrm{DMSO}-d_{6}\right) \delta$ $1.32\left(3 \mathrm{H}, \mathrm{t}, J=8.0 \mathrm{~Hz}, \mathrm{CO}_{2} \mathrm{CH}_{2} \mathrm{CH}_{3}\right), 1.79-1.82(4 \mathrm{H}, \mathrm{m}, 2 \times-$ $\left.\mathrm{CH}_{2}-\right)$, 3.80-3.86 (5H, m, $\mathrm{OCH}_{3}$ and $\left.-\mathrm{CH}_{2}-\right), 4.07(2 \mathrm{H}, \mathrm{t}$, $\left.J=8.0 \mathrm{~Hz},-\mathrm{CH}_{2}-\right), 4.34\left(2 \mathrm{H}, \mathrm{q}, J=8.0 \mathrm{~Hz}, \mathrm{CO}_{2} \mathrm{CH}_{2} \mathrm{CH}_{3}\right)$,
$6.97(1 \mathrm{H}, \mathrm{dd}, J=4.0,8.0 \mathrm{~Hz}, \mathrm{Ar}-\mathrm{H}), 7.06-7.11(3 \mathrm{H}, \mathrm{m}, \mathrm{Ar}-\mathrm{H})$, $7.16(1 \mathrm{H}, \mathrm{d}, J=8.0 \mathrm{~Hz}, \mathrm{Ar}-\mathrm{H}), 7.41-7.44(2 \mathrm{H}, \mathrm{m}, \mathrm{Ar}-\mathrm{H}), 7.56$ $(1 \mathrm{H}, \mathrm{d}, J=8.0 \mathrm{~Hz}, \mathrm{Ar}-\mathrm{H}), 7.96(2 \mathrm{H}, \mathrm{d}, J=8.0 \mathrm{~Hz}, \mathrm{Ar}-\mathrm{H}), 8.00$ $(1 \mathrm{H}, \mathrm{d}, J=8.0 \mathrm{~Hz}, \mathrm{Ar}-\mathrm{H}), 13.42(1 \mathrm{H}, \mathrm{s}, \mathrm{NOH})$. ESI-MS m/z: $551[\mathrm{M}+\mathrm{Na}]^{+}$. 

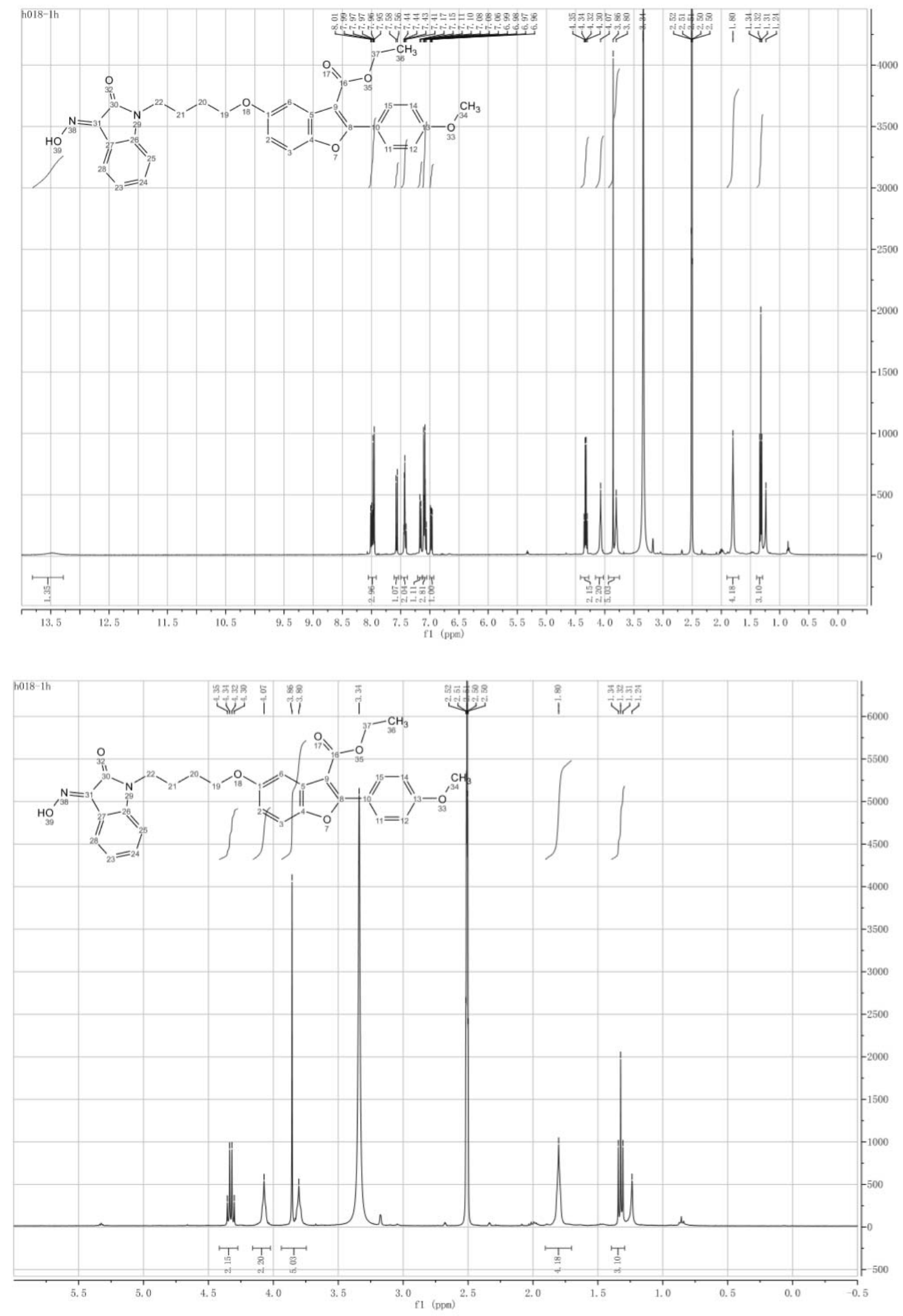
700

Yin-Ling Wang et al.

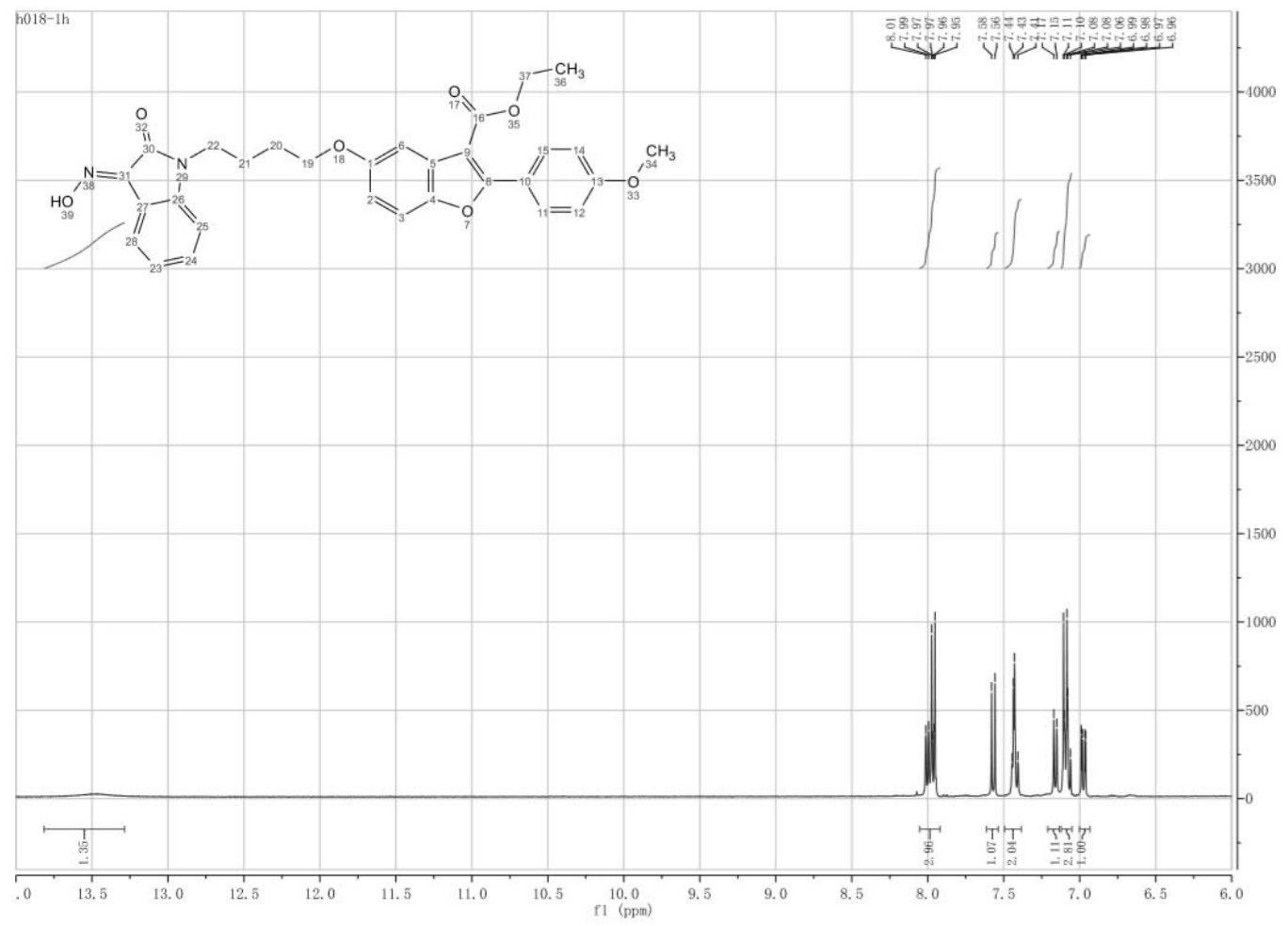

Ethyl 5-((5-(3-(hydroxyimino)-2-oxoindolin-1-yl)pentyl)oxy)2-(4-methoxyphenyl)benzofuran-3-carboxylate (Go)

Yellow solid, yield: $33 \% .{ }^{1} \mathrm{H}$ NMR (400 MHz, DMSO- $\left.d_{6}\right) \delta$ $1.31\left(3 \mathrm{H}, \mathrm{t}, J=8.0 \mathrm{~Hz}, \mathrm{CO}_{2} \mathrm{CH}_{2} \mathrm{CH}_{3}\right), 1.48(2 \mathrm{H}, \mathrm{t}, J=8.0 \mathrm{~Hz}$, $\left.-\mathrm{CH}_{2}-\right), 1.67\left(2 \mathrm{H}, \mathrm{t}, J=8.0 \mathrm{~Hz},-\mathrm{CH}_{2}-\right), 1.79(2 \mathrm{H}, \mathrm{t}, J=8.0$ $\left.\mathrm{Hz},-\mathrm{CH}_{2}-\right), 3.74\left(2 \mathrm{H}, \mathrm{t}, J=8.0 \mathrm{~Hz},-\mathrm{CH}_{2}-\right), 3.85(3 \mathrm{H}, \mathrm{s}$,
$\left.\mathrm{OCH}_{3}\right), 4.00\left(2 \mathrm{H}, \mathrm{t}, J=8.0 \mathrm{~Hz},-\mathrm{CH}_{2}-\right), 4.32(2 \mathrm{H}, \mathrm{q}, J=8.0 \mathrm{~Hz}$, $\left.\mathrm{CO}_{2} \mathrm{CH}_{2} \mathrm{CH}_{3}\right), 6.96(1 \mathrm{H}, \mathrm{dd}, J=4.0,8.0 \mathrm{~Hz}, \mathrm{Ar}-\mathrm{H}), 7.07-7.10$ $(3 \mathrm{H}, \mathrm{m}, \mathrm{Ar}-\mathrm{H}), 7.12(1 \mathrm{H}, \mathrm{d}, J=8.0 \mathrm{~Hz}, \mathrm{Ar}-\mathrm{H}), 7.40-7.42(2 \mathrm{H}$, $\mathrm{m}, \operatorname{Ar}-\mathrm{H}), 7.56(1 \mathrm{H}, \mathrm{d}, J=8.0 \mathrm{~Hz}, \mathrm{Ar}-\mathrm{H}), 7.96(2 \mathrm{H}, \mathrm{d}, J=8.0$ $\mathrm{Hz}, \mathrm{Ar}-\mathrm{H}), 8.00(1 \mathrm{H}, \mathrm{d}, J=8.0 \mathrm{~Hz}, \mathrm{Ar}-\mathrm{H}), 13.44(1 \mathrm{H}, \mathrm{s}$, $\mathrm{NOH})$. ESI-MS m/z: $565[\mathrm{M}+\mathrm{Na}]^{+}$.

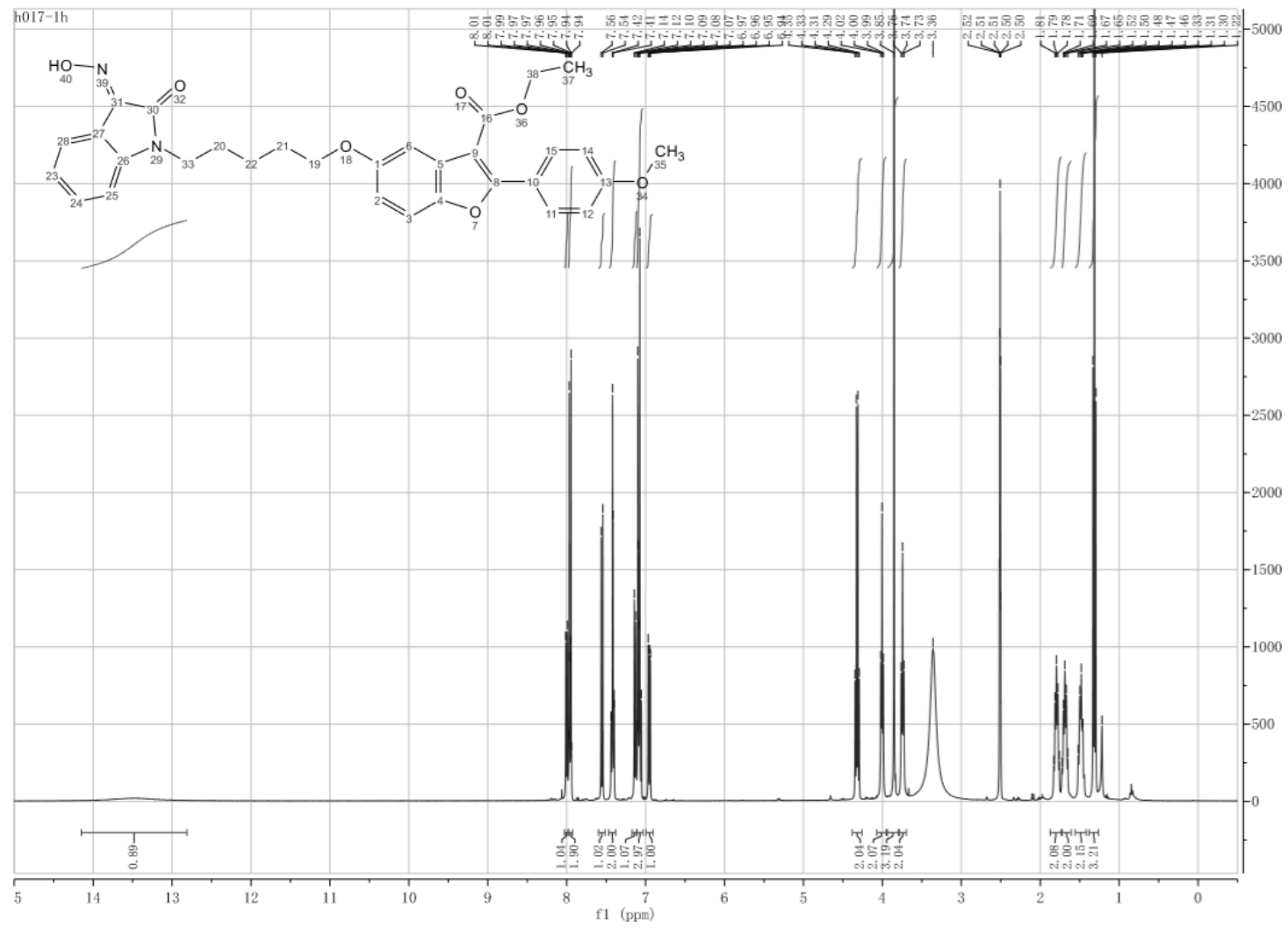



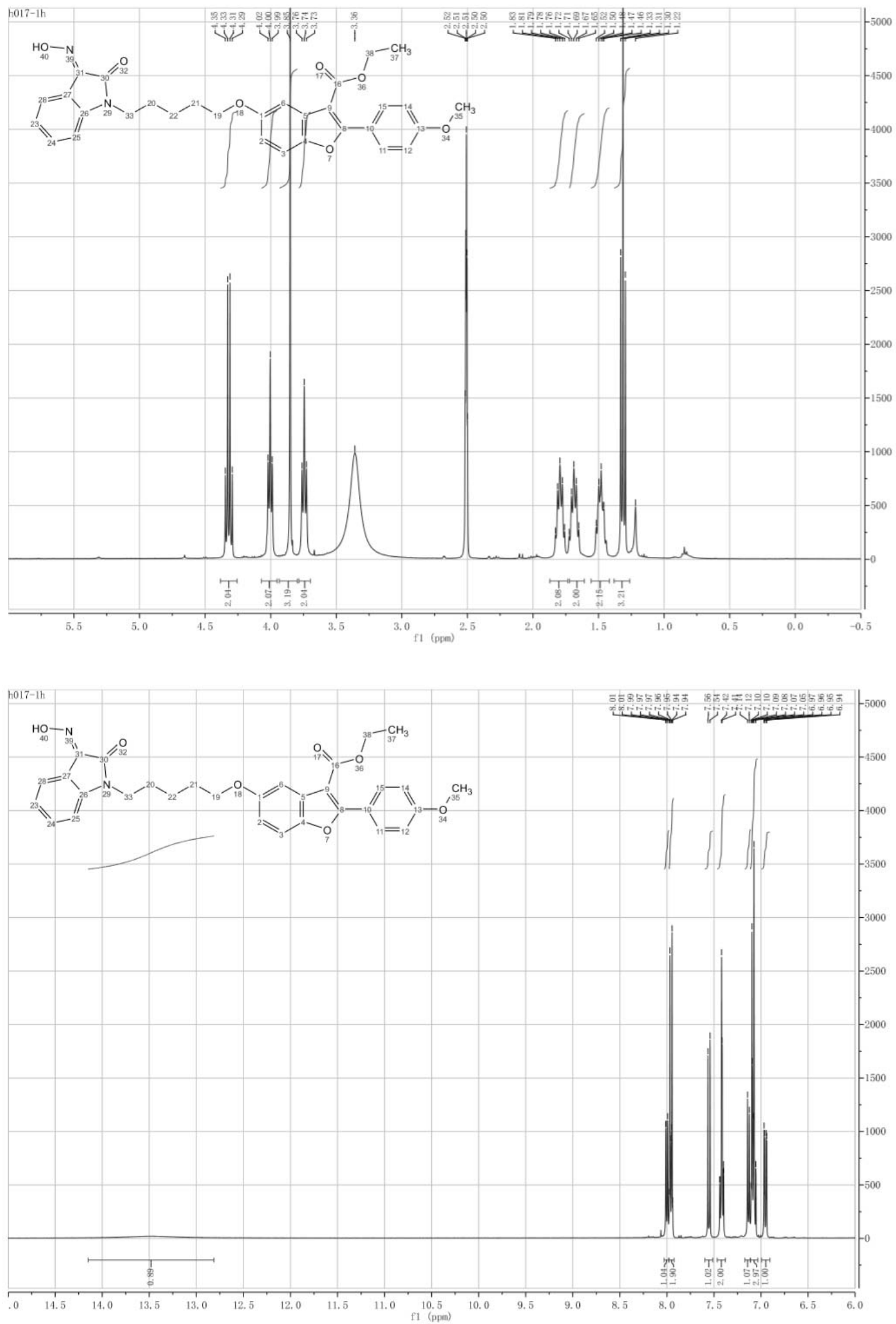

Ethyl 2-(4-fluorophenyl)-5-(3-(3-(hydroxyimino)-2-oxoindolin-1-yl)propoxy)benzofuran-3-carboxylate (6p)

Yellow solid, yield: $54 \% .{ }^{1} \mathrm{H}$ NMR $\left(400 \mathrm{MHz}, \mathrm{DMSO}-d_{6}\right) \delta$

$1.30\left(3 \mathrm{H}, \mathrm{t}, J=8.0 \mathrm{~Hz}, \mathrm{CO}_{2} \mathrm{CH}_{2} \mathrm{CH}_{3}\right), 2.21(2 \mathrm{H}, \mathrm{t}, J=8.0 \mathrm{~Hz}$,

$\left.-\mathrm{CH}_{2}-\right), 3.93\left(2 \mathrm{H}, \mathrm{t}, J=8.0 \mathrm{~Hz},-\mathrm{CH}_{2}^{-}\right), 4.09(2 \mathrm{H}, \mathrm{t}, J=8.0 \mathrm{~Hz}$,
$\left.-\mathrm{CH}_{2}-\right), 4.34\left(2 \mathrm{H}, \mathrm{q}, J=8.0 \mathrm{~Hz}, \mathrm{CO}_{2} \mathrm{CH}_{2} \mathrm{CH}_{3}\right), 6.98(1 \mathrm{H}, \mathrm{dd}$, $J=4.0,8.0 \mathrm{~Hz}, \mathrm{Ar}-\mathrm{H}), 7.08(1 \mathrm{H}, \mathrm{t}, J=8.0 \mathrm{~Hz}, \mathrm{Ar}-\mathrm{H}), 7.16$ $(1 \mathrm{H}, \mathrm{d}, J=8.0 \mathrm{~Hz}, \mathrm{Ar}-\mathrm{H}), 7.39-7.43(4 \mathrm{H}, \mathrm{m}, \mathrm{Ar}-\mathrm{H}), 7.60(1 \mathrm{H}$, d, $J=12.0 \mathrm{~Hz}, \mathrm{Ar}-\mathrm{H}), 7.99-8.06(3 \mathrm{H}, \mathrm{m}, \mathrm{Ar}-\mathrm{H}), 13.44(1 \mathrm{H}, \mathrm{s}$, $\mathrm{NOH})$. ESI-MS m/z: $525[\mathrm{M}+\mathrm{Na}]^{+}$. 

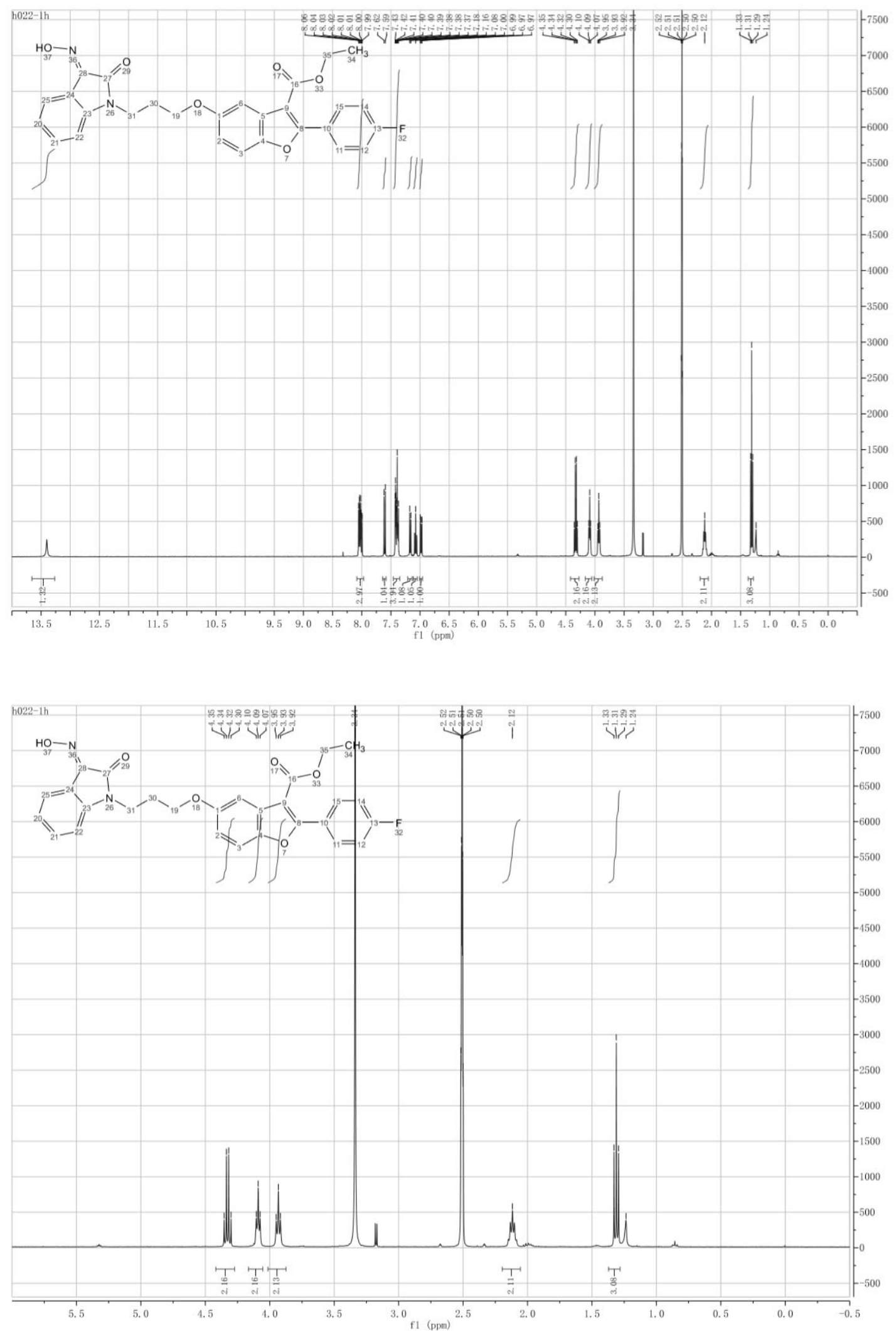
Benzofuran-isatin hybrid

703

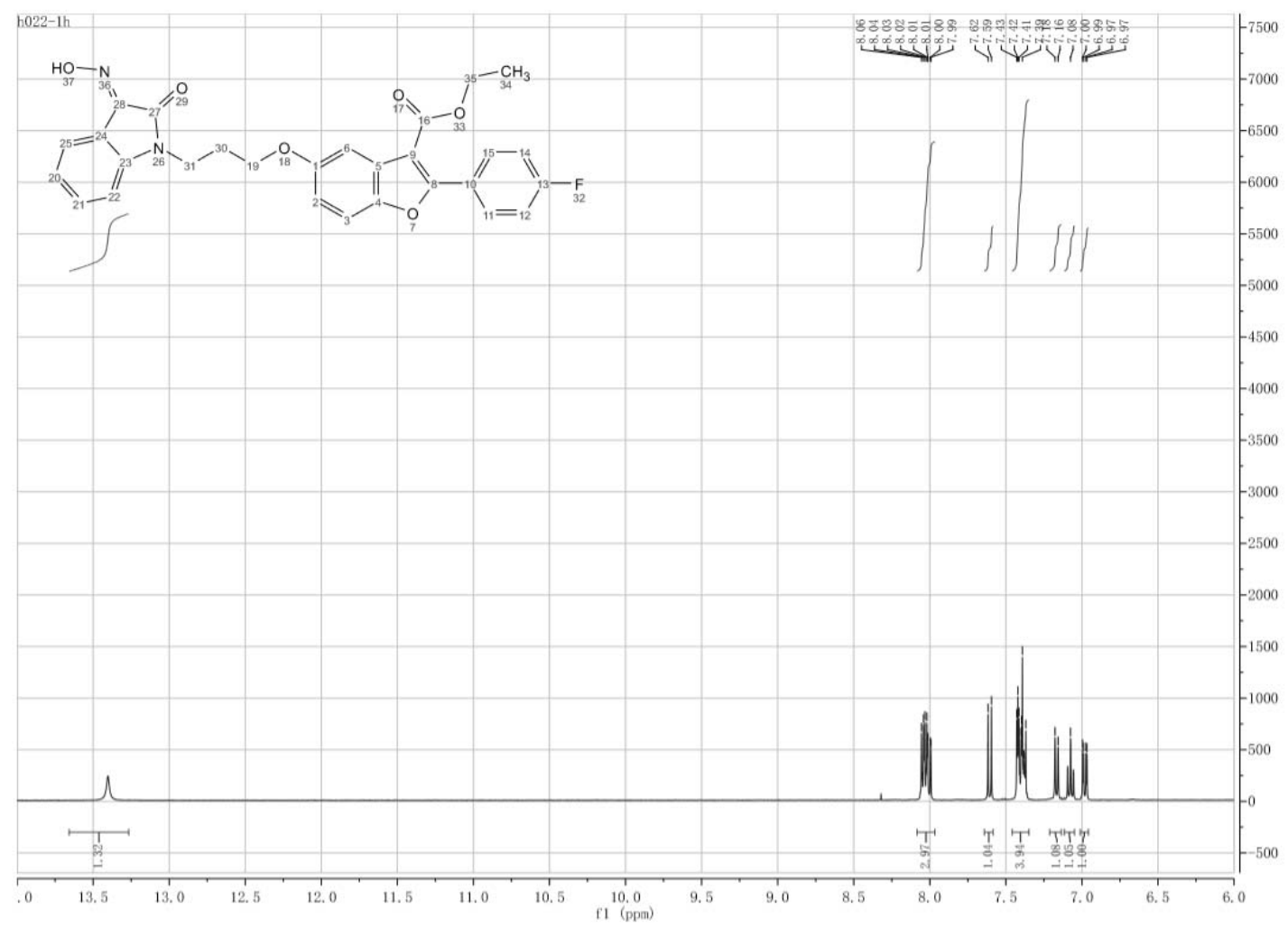

Ethyl 5-(3-(3-(2-carbamothioylhydrazono)-2-oxoindolin-1yl)propoxy)-2-(4-methoxyphenyl)benzofuran-3- carboxylate (6q) Yellow solid, yield: $36 \%$. ${ }^{1} \mathrm{H}$ NMR $\left(400 \mathrm{MHz}, \mathrm{DMSO}-d_{6}\right) \delta$ $1.32\left(3 \mathrm{H}, \mathrm{t}, J=8.0 \mathrm{~Hz}, \mathrm{CO}_{2} \mathrm{CH}_{2} \mathrm{CH}_{3}\right), 2.15(2 \mathrm{H}, \mathrm{t}, J=8.0 \mathrm{~Hz}$, $\left.-\mathrm{CH}_{2}-\right), 3.86\left(3 \mathrm{H}, \mathrm{s}, \mathrm{OCH}_{3}\right), 3.97\left(2 \mathrm{H}, \mathrm{t}, J=8.0 \mathrm{~Hz},-\mathrm{CH}_{2}-\right)$, $4.11\left(2 \mathrm{H}, \mathrm{t}, J=8.0 \mathrm{~Hz},-\mathrm{CH}_{2}-\right), 4.32(2 \mathrm{H}, \mathrm{q}, J=8.0 \mathrm{~Hz}$,
$\left.\mathrm{CO}_{2} \mathrm{CH}_{2} \mathrm{CH}_{3}\right), 6.95(1 \mathrm{H}, \mathrm{dd}, J=4.0,8.0 \mathrm{~Hz}, \mathrm{Ar}-\mathrm{H}), 7.08-7.14$ $(3 \mathrm{H}, \mathrm{m}, \mathrm{Ar}-\mathrm{H}), 7.22(1 \mathrm{H}, \mathrm{t}, J=8.0 \mathrm{~Hz}, \mathrm{Ar}-\mathrm{H}), 7.39-7.42(2 \mathrm{H}$, $\mathrm{m}, \operatorname{Ar}-\mathrm{H}), 7.55(1 \mathrm{H}, \mathrm{d}, J=12.0 \mathrm{~Hz}, \operatorname{Ar}-\mathrm{H}), 7.71(1 \mathrm{H}, \mathrm{d}$, $J=8.0 \mathrm{~Hz}$, Ar-H), $7.96(2 \mathrm{H}, \mathrm{d}, J=8.0 \mathrm{~Hz}, \mathrm{Ar}-\mathrm{H}), 8.71,9.07$ $\left(2 \mathrm{H}, \mathrm{s}, \mathrm{NNHCSNH}_{2}\right), 12.38\left(1 \mathrm{H}, \mathrm{s}, \mathrm{NNHCSNH}_{2}\right)$. ESI-MS $\mathrm{m} / \mathrm{z}: 595[\mathrm{M}+\mathrm{Na}]^{+}$.

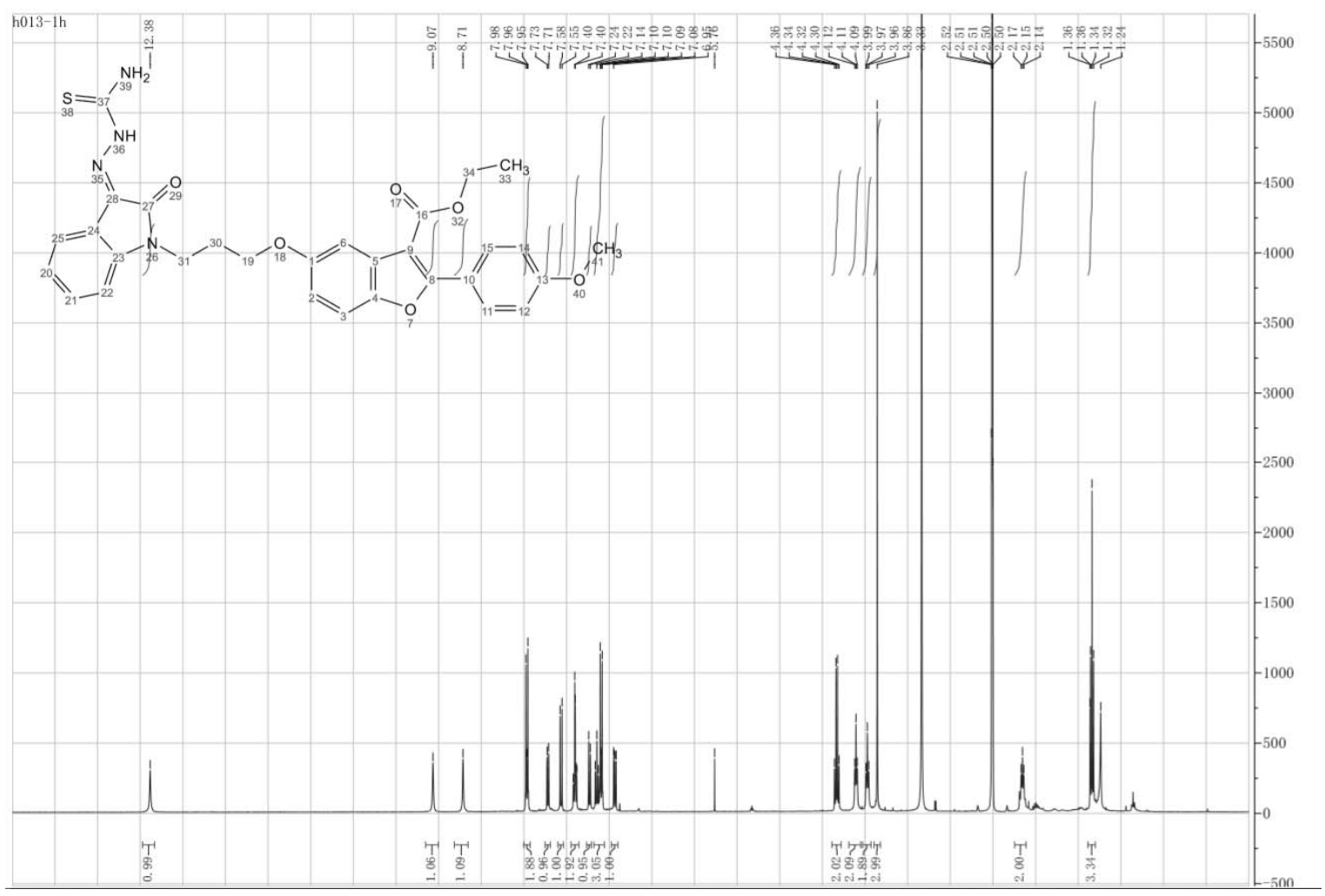




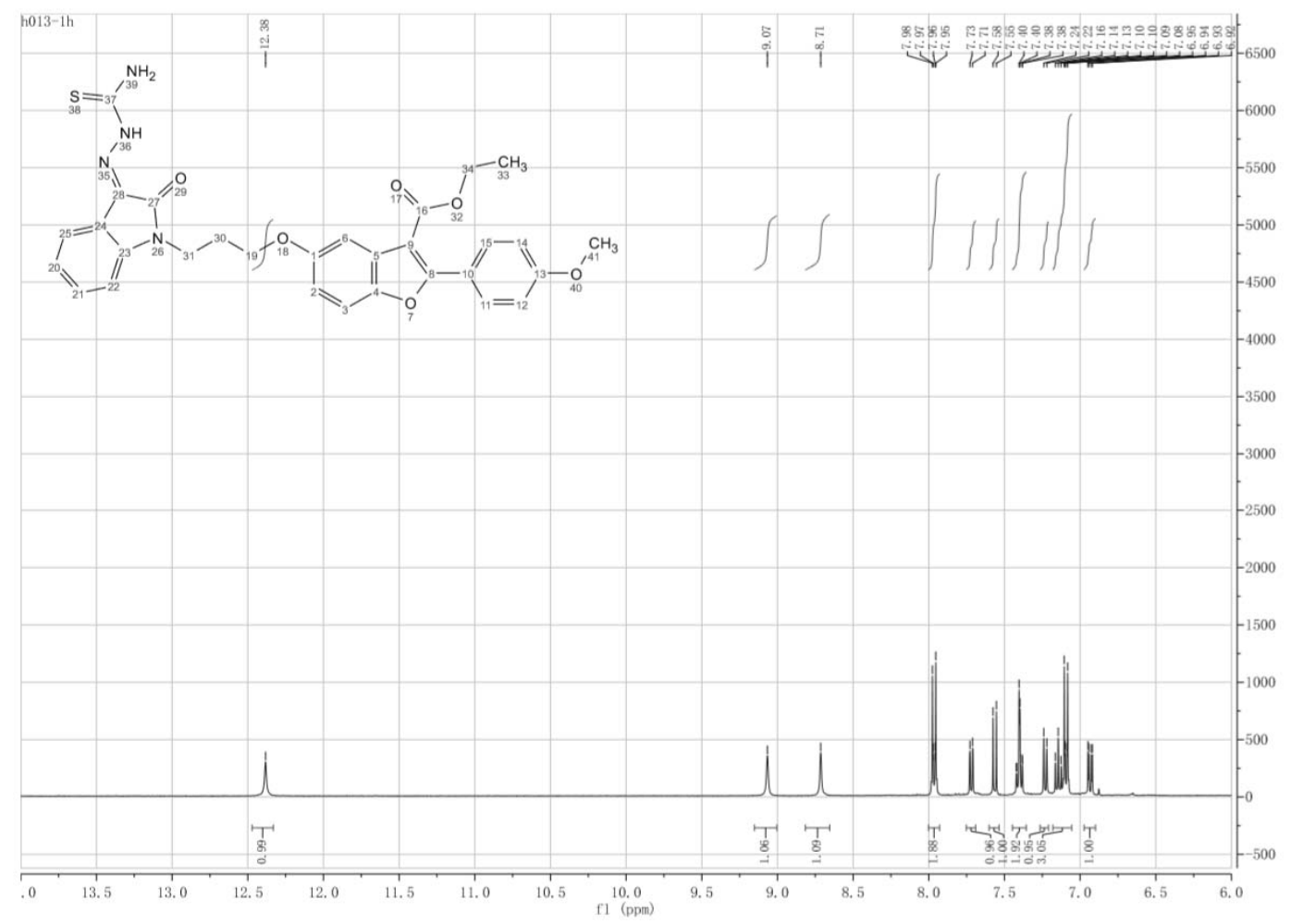

Ethyl 5-(4-(3-(2-carbamothioylhydrazono)-2-oxoindolin-1-yl)butoxy)-2-(4-methoxyphenyl)benzofuran-3-carboxylate (6r)

Yellow solid, yield: $24 \% .{ }^{1} \mathrm{H}$ NMR (400 MHz, DMSO- $\left.d_{6}\right) \delta$ $1.33\left(3 \mathrm{H}, \mathrm{t}, J=8.0 \mathrm{~Hz}, \mathrm{CO}_{2} \mathrm{CH}_{2} \mathrm{CH}_{3}\right), 1.79-1.82(4 \mathrm{H}, \mathrm{m}, 2 \times-$ $\left.\mathrm{CH}_{2-}\right), 3.82-3.86\left(5 \mathrm{H}, \mathrm{m},-\mathrm{CH}_{2-}\right.$ and $\left.\mathrm{OCH}_{3}\right), 4.06(2 \mathrm{H}, \mathrm{t}$, $\left.J=8.0 \mathrm{~Hz},-\mathrm{CH}_{2}-\right), 4.33\left(2 \mathrm{H}, \mathrm{q}, J=8.0 \mathrm{~Hz}, \mathrm{CO}_{2} \mathrm{CH}_{2} \mathrm{CH}_{3}\right)$,
$6.96(1 \mathrm{H}, \mathrm{dd}, J=4.0,8.0 \mathrm{~Hz}, \mathrm{Ar}-\mathrm{H}), 7.08(1 \mathrm{H}, \mathrm{dd}, J=4.0,8.0 \mathrm{~Hz}$, Ar-H), $7.15(1 \mathrm{H}, \mathrm{t}, J=8.0 \mathrm{~Hz}, \mathrm{Ar}-\mathrm{H}), 7.23(1 \mathrm{H}, \mathrm{d}, J=8.0 \mathrm{~Hz}, \mathrm{Ar}-$ H), 7.41-7.43 (2H, m, Ar-H), $7.53(1 \mathrm{H}, \mathrm{d}, J=12.0 \mathrm{~Hz}, \mathrm{Ar}-\mathrm{H})$, $7.70(1 \mathrm{H}, \mathrm{d}, J=8.0 \mathrm{~Hz}, \mathrm{Ar}-\mathrm{H}), 7.96(2 \mathrm{H}, \mathrm{d}, J=8.0 \mathrm{~Hz}, \mathrm{Ar}-\mathrm{H})$, 8.72, $9.09\left(2 \mathrm{H}, \mathrm{s}, \mathrm{NNHCSNH}_{2}\right), 12.43\left(1 \mathrm{H}, \mathrm{s}, \mathrm{NNHCSNH}_{2}\right)$. ESI-MS m/z: $609[\mathrm{M}+\mathrm{Na}]^{+}$.

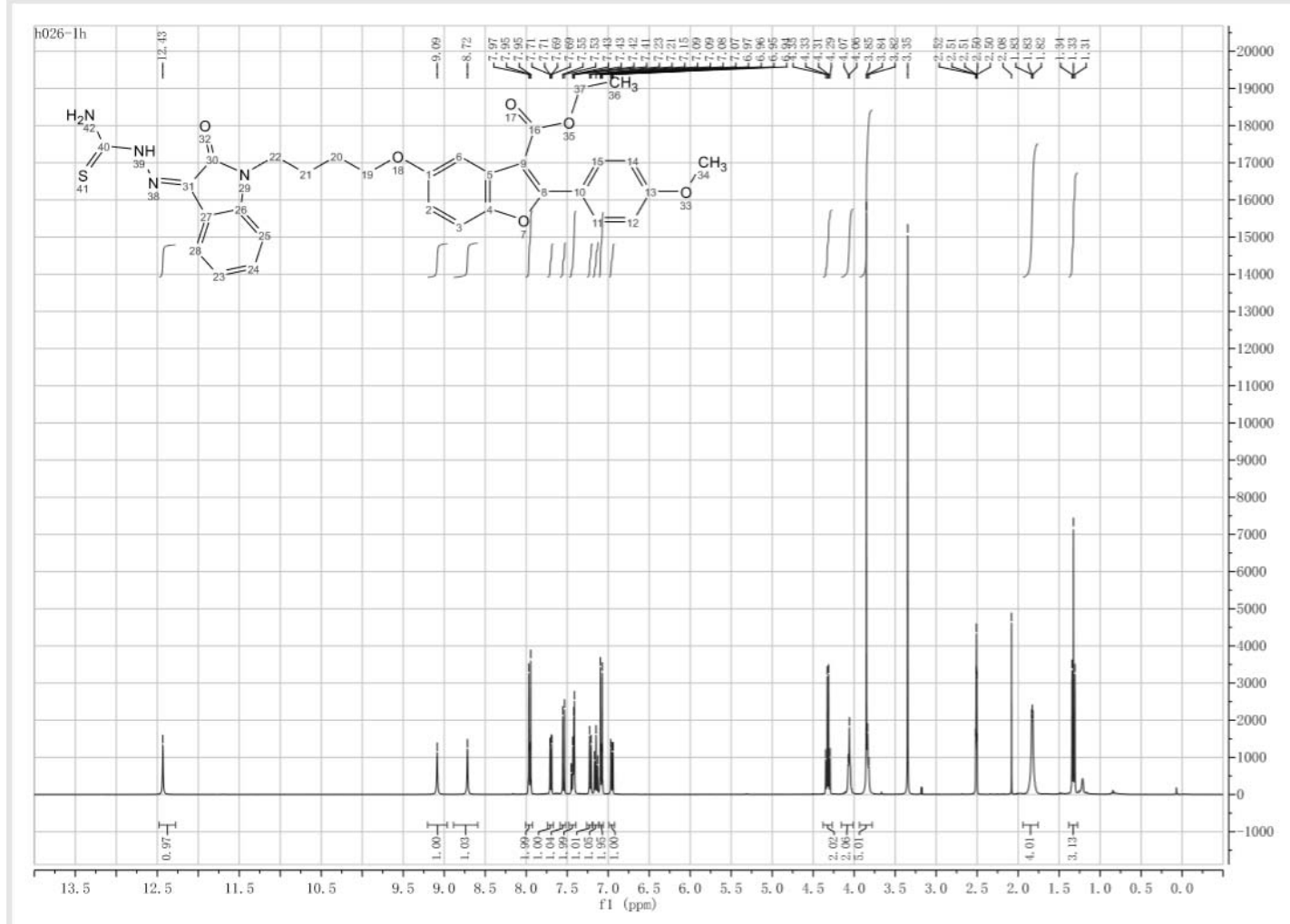



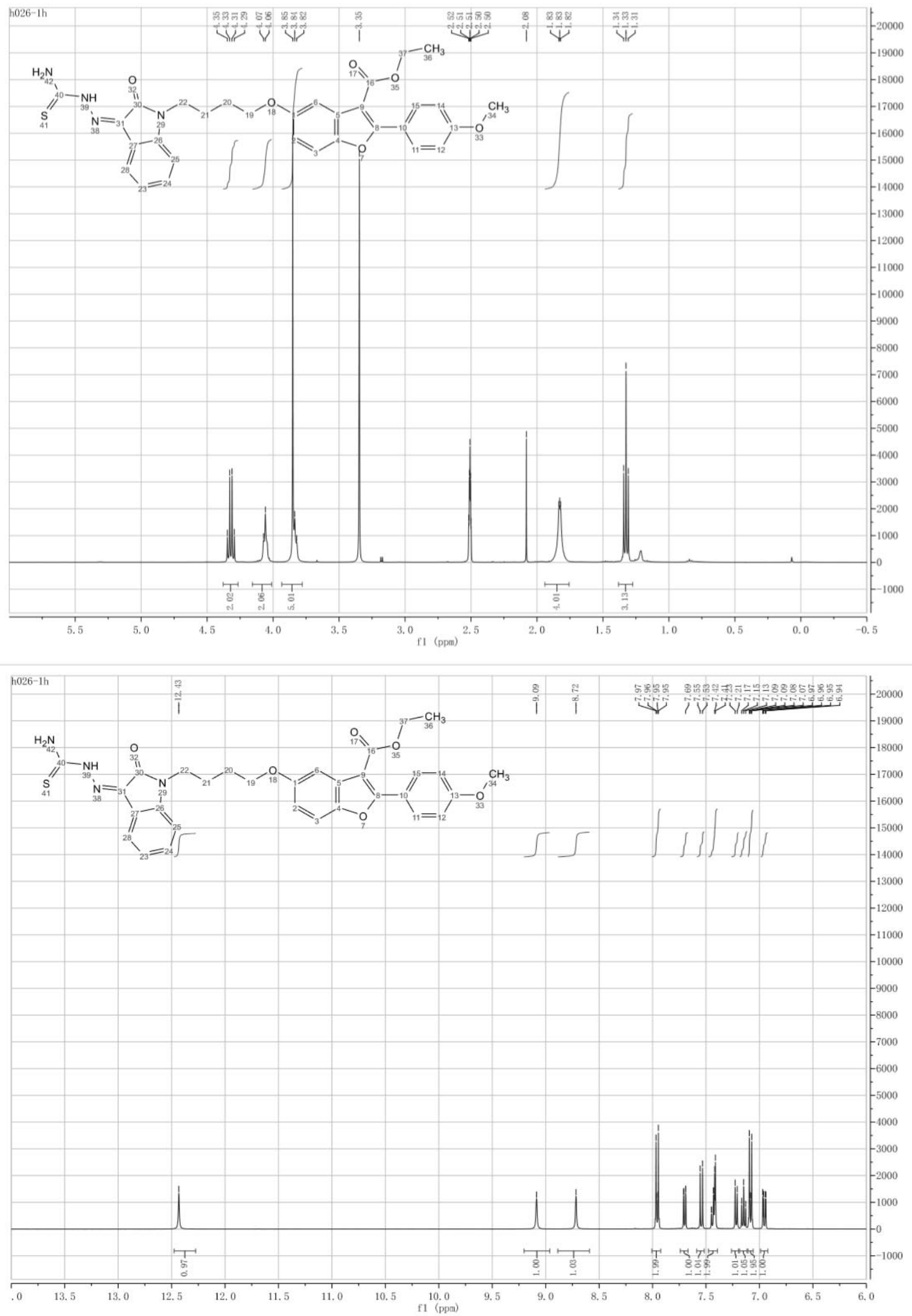

Ethyl(E)-5-((5-(3-(2-carbamothioylhydrazono)-2-oxoindolin1-yl)pentyl)oxy)-2-(4-methoxyphenyl)benzofuran-3-carboxylate (6s)

Yellow solid, yield: $19 \%$. ${ }^{1} \mathrm{H}$ NMR (400 MHz, DMSO- $\left.d_{6}\right) \delta$ $1.32\left(3 \mathrm{H}, \mathrm{t}, J=8.0 \mathrm{~Hz}, \mathrm{CO}_{2} \mathrm{CH}_{2} \mathrm{CH}_{3}\right), 1.42-1.82(6 \mathrm{H}, \mathrm{m}, 3 \times-$ $\left.\mathrm{CH}_{2}-\right), 3.80-3.86\left(5 \mathrm{H}, \mathrm{m},-\mathrm{CH}_{2-}^{-}\right.$and $\left.\mathrm{OCH}_{3}\right), 4.02(2 \mathrm{H}, \mathrm{t}$, $\left.J=8.0 \mathrm{~Hz},-\mathrm{CH}_{2}-\right), 4.34\left(2 \mathrm{H}, \mathrm{q}, J=8.0 \mathrm{~Hz}, \mathrm{CO}_{2} \mathrm{CH}_{2} \mathrm{CH}_{3}\right)$,
$6.96(1 \mathrm{H}, \mathrm{dd}, J=4.0,8.0 \mathrm{~Hz}, \mathrm{Ar}-\mathrm{H}), 7.08(1 \mathrm{H}, \mathrm{dd}, J=4.0,8.0 \mathrm{~Hz}$, Ar-H), $7.15(1 \mathrm{H}, \mathrm{t}, J=8.0 \mathrm{~Hz}, \mathrm{Ar}-\mathrm{H}), 7.22(1 \mathrm{H}, \mathrm{d}, J=8.0 \mathrm{~Hz}, \mathrm{Ar}-$ $\mathrm{H}), 7.41-7.43(2 \mathrm{H}, \mathrm{m}, \mathrm{Ar}-\mathrm{H}), 7.57(1 \mathrm{H}, \mathrm{d}, J=12.0 \mathrm{~Hz}, \mathrm{Ar}-\mathrm{H})$, $7.72(1 \mathrm{H}, \mathrm{d}, J=8.0 \mathrm{~Hz}, \mathrm{Ar}-\mathrm{H}), 7.96(2 \mathrm{H}, \mathrm{d}, J=8.0 \mathrm{~Hz}, \mathrm{Ar}-\mathrm{H})$, 8.73, $9.08\left(2 \mathrm{H}, \mathrm{s}, \mathrm{NNHCSNH}_{2}\right), 12.44\left(1 \mathrm{H}, \mathrm{s}, \mathrm{NNHCSNH}_{2}\right)$. ESI-MS m/z: $623[\mathrm{M}+\mathrm{Na}]^{+}$. 


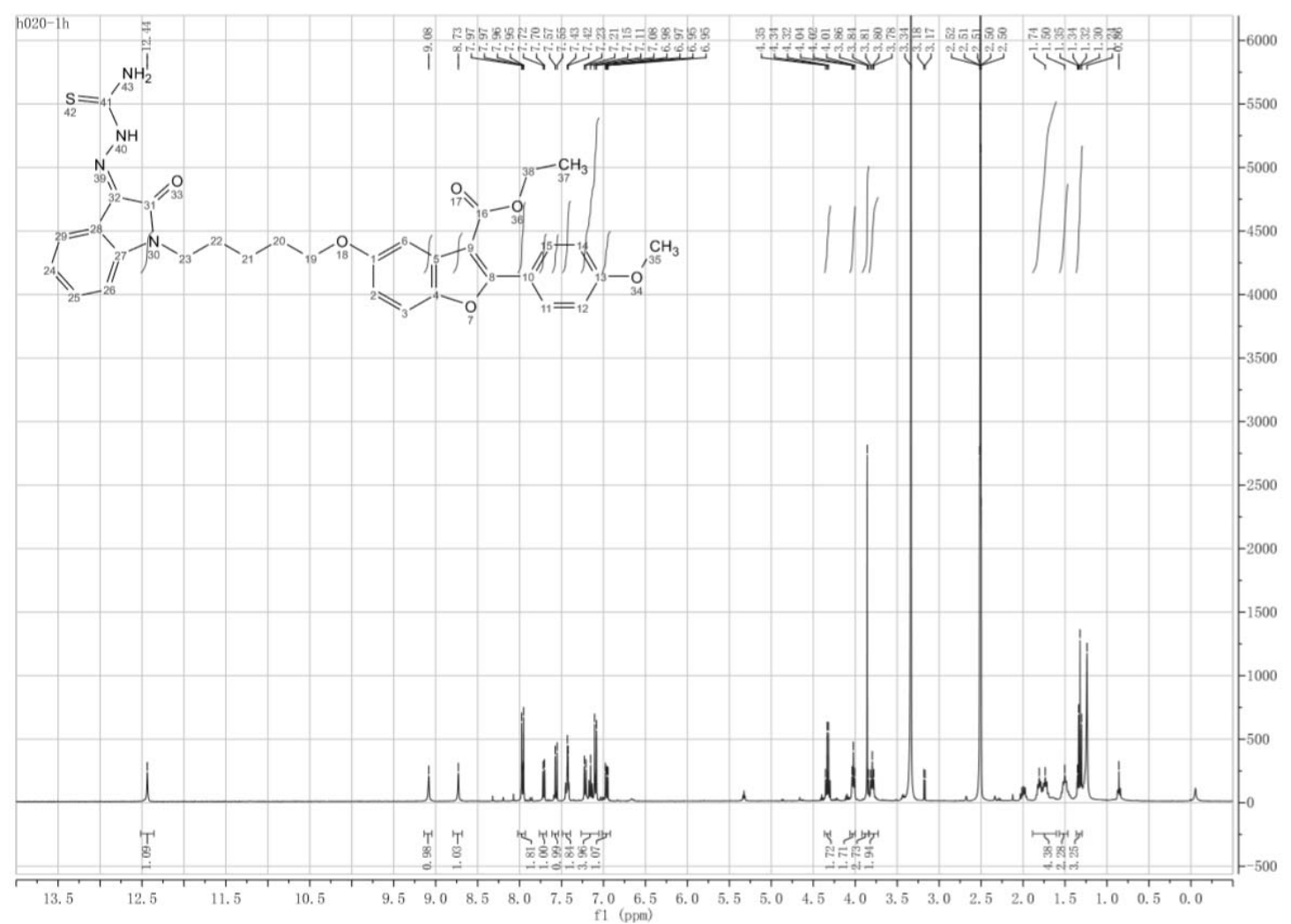

Ethyl 5-(3-(5-fluoro-3-(hydroxyimino)-2-oxoindolin-1-yl)propoxy)-2-phenylbenzofuran-3-carboxylate (6t)

Yellow solid, yield: $48 \%{ }^{1} \mathrm{H}$ NMR $\left(400 \mathrm{MHz}, \mathrm{DMSO}-d_{6}\right) \delta$

$1.28\left(3 \mathrm{H}, \mathrm{t}, J=8.0 \mathrm{~Hz}, \mathrm{CO}_{2} \mathrm{CH}_{2} \underline{\mathrm{CH}}_{3}\right), 2.08(2 \mathrm{H}, \mathrm{t}, J=8.0 \mathrm{~Hz}$,
$\left.-\mathrm{CH}_{2}-\right), 3.94\left(2 \mathrm{H}, \mathrm{t}, J=8.0 \mathrm{~Hz},-\mathrm{CH}_{2}-\right), 4.12(2 \mathrm{H}, \mathrm{t}, J=8.0 \mathrm{~Hz},-$ $\left.\mathrm{CH}_{2}-\right), 4.48\left(2 \mathrm{H}, \mathrm{q}, J=8.0 \mathrm{~Hz}, \mathrm{CO}_{2} \mathrm{CH}_{2} \mathrm{CH}_{3}\right), 6.96-7.29(3 \mathrm{H}$, m, Ar-H), 7.39-7.96 (8H, m, Ar-H), 13.70 (1H, s, NOH). ESI$\mathrm{MS}$ m/z: $525[\mathrm{M}+\mathrm{Na}]^{+}$.

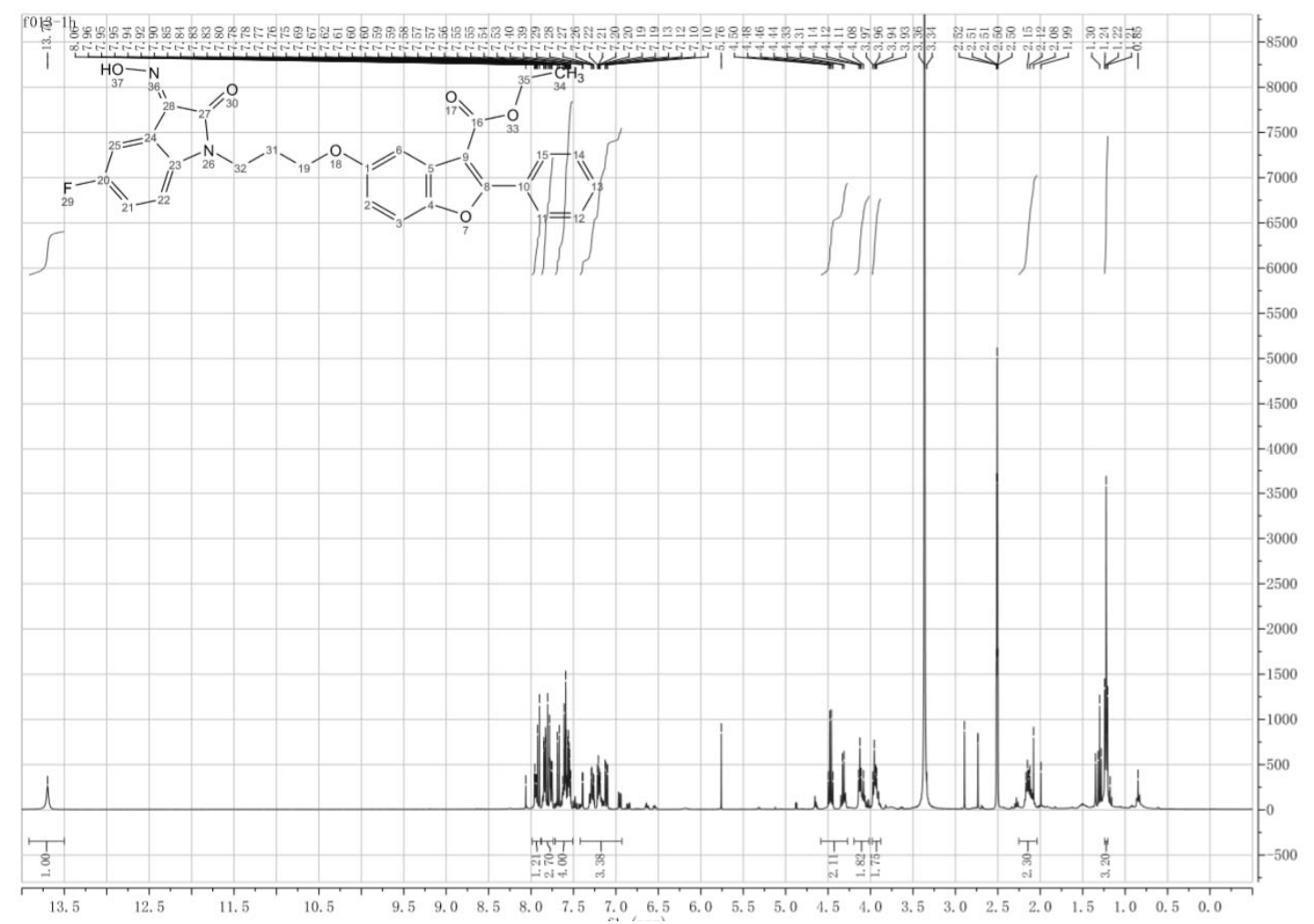


Ethyl 5-(3-(5-fluoro-3-(hydroxyimino)-2-oxoindolin-1-yl)propoxy) -2-(4-fluorophenyl)benzofuran-3carboxylate $(\mathbf{6 u})$

Yellow solid, yield: $39 \% .{ }^{1} \mathrm{H}$ NMR (400 MHz, DMSO- $\left.d_{6}\right) \delta$ $1.31\left(3 \mathrm{H}, \mathrm{t}, J=8.0 \mathrm{~Hz}, \mathrm{CO}_{2} \mathrm{CH}_{2} \mathrm{CH}_{3}\right), 2.11(2 \mathrm{H}, \mathrm{t}, J=8.0 \mathrm{~Hz}$, $\left.-\mathrm{CH}_{2}-\right), 3.93\left(2 \mathrm{H}, \mathrm{t}, J=8.0 \mathrm{~Hz},-\mathrm{CH}_{2}-\right), 4.09(2 \mathrm{H}, \mathrm{t}, J=8.0 \mathrm{~Hz},-$
$\left.\mathrm{CH}_{2}-\right), 4.34\left(2 \mathrm{H}, \mathrm{q}, J=8.0 \mathrm{~Hz}, \mathrm{CO}_{2} \mathrm{CH}_{2} \mathrm{CH}_{3}\right), 6.96(1 \mathrm{H}, \mathrm{dd}$, $J=4.0,8.0 \mathrm{~Hz}, \mathrm{Ar}-\mathrm{H}), 7.18-7.31(2 \mathrm{H}, \mathrm{m}, \mathrm{Ar}-\mathrm{H}), 7.36-7.42$ $(3 \mathrm{H}, \mathrm{m}, \mathrm{Ar}-\mathrm{H}), 7.60(1 \mathrm{H}, \mathrm{d}, J=12.0 \mathrm{~Hz}, \mathrm{Ar}-\mathrm{H}), 7.76(1 \mathrm{H}, \mathrm{d}$, $J=8.0 \mathrm{~Hz}$, Ar-H), 8.01-8.05 (2H, m, Ar-H), $13.68(1 \mathrm{H}, \mathrm{s}$, $\mathrm{NOH})$. ESI-MS m/z: $543[\mathrm{M}+\mathrm{Na}]^{+}$.
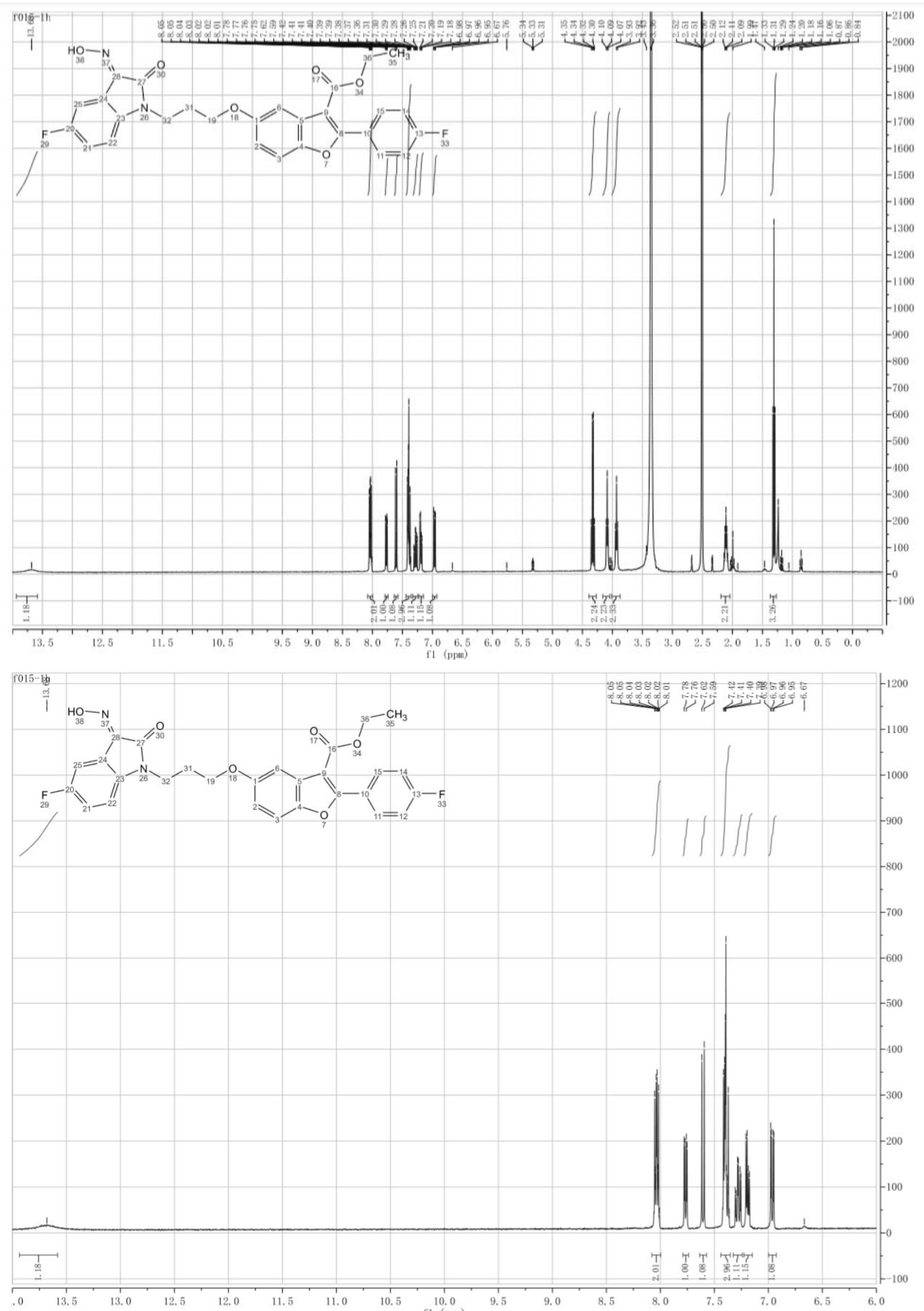
Ethyl 5-(3-(3-(hydroxyimino)-5-methoxy-2-oxoindolin-1-yl)propoxy) -2-phenylbenzofuran-3-carboxylate (6v)

Yellow solid, yield: $46 \%$. ${ }^{1} \mathrm{H}$ NMR (400 MHz, DMSO- $\left.d_{6}\right) \delta$

$1.24\left(3 \mathrm{H}, \mathrm{t}, J=8.0 \mathrm{~Hz}, \mathrm{CO}_{2} \mathrm{CH}_{2} \mathrm{CH}_{3}\right), 2.15(2 \mathrm{H}, \mathrm{t}, J=8.0 \mathrm{~Hz}$, $\left.-\mathrm{CH}_{2}-\right), 3.74\left(3 \mathrm{H}, \mathrm{s}, \mathrm{OCH}_{3}\right), 3.93\left(2 \mathrm{H}, \mathrm{t}, J=8.0 \mathrm{~Hz},-\mathrm{CH}_{2^{-}}\right)$, $4.12\left(2 \mathrm{H}, \mathrm{t}, J=8.0 \mathrm{~Hz},-\mathrm{CH}_{2}-\right), 4.46(2 \mathrm{H}, \mathrm{q}, J=8.0 \mathrm{~Hz}$, $\left.\mathrm{CO}_{2} \mathrm{CH}_{2} \mathrm{CH}_{3}\right), 6.98(1 \mathrm{H}, \mathrm{dd}, J=4.0,8.0 \mathrm{~Hz}, \mathrm{Ar}-\mathrm{H}), 7.08-7.15$ $(2 \mathrm{H}, \mathrm{m}, \mathrm{Ar}-\mathrm{H}), 7.54-7.70(5 \mathrm{H}, \mathrm{m}, \mathrm{Ar}-\mathrm{H}), 7.80-7.96(3 \mathrm{H}, \mathrm{m}$, Ar-H), 13.46 (1H, s, NOH). ESI-MS m/z: $537[\mathrm{M}+\mathrm{Na}]^{+}$.

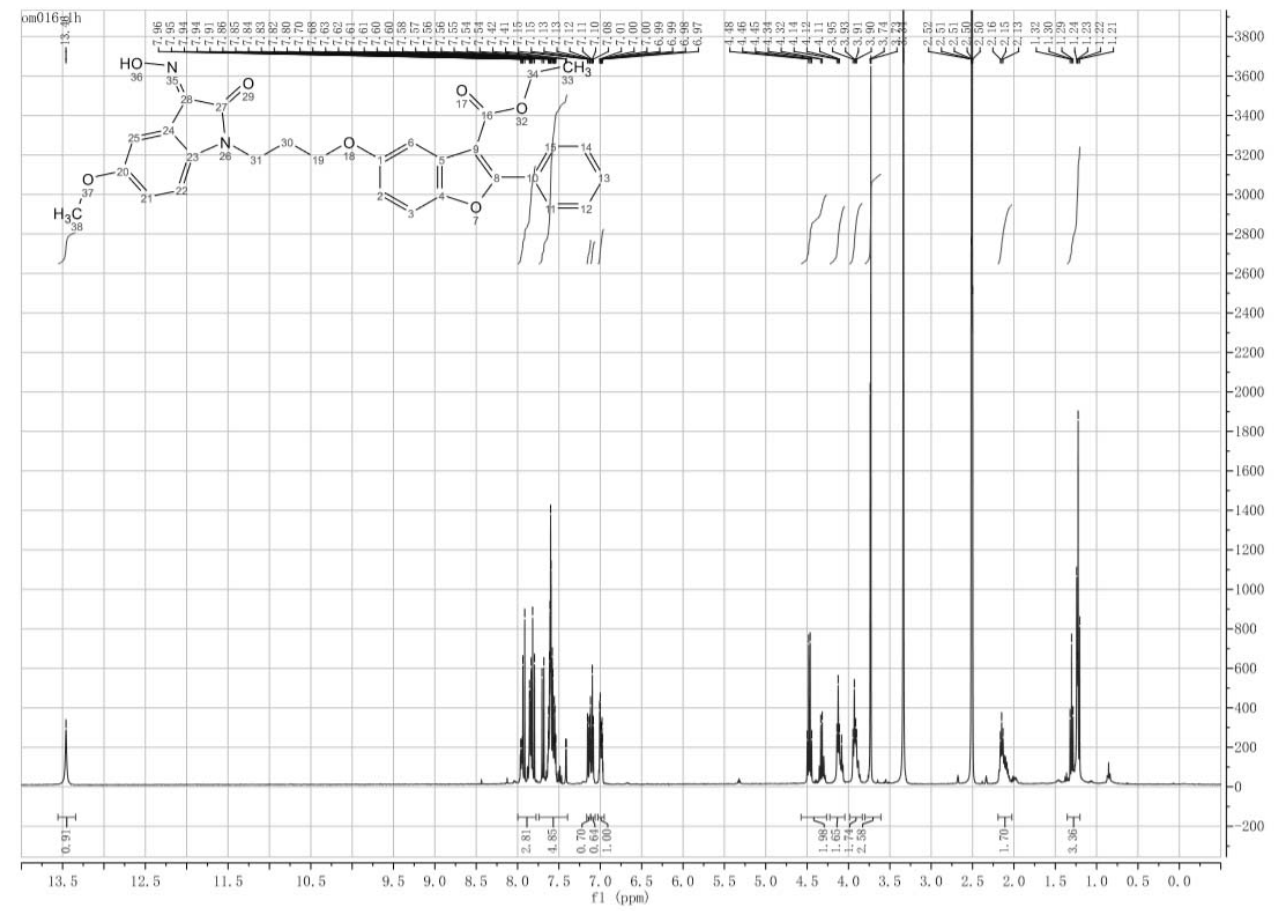

Ethyl2-(4-fluorophenyl)-5-(3-(3-(hydroxyimino)-5-methoxy-2oxoindolin-1-yl)propoxy)benzofuran-3-carboxylate (6w) Yellow solid, yield: $43 \% .{ }^{1} \mathrm{H}$ NMR $\left(400 \mathrm{MHz}\right.$, DMSO- $\left.d_{6}\right) \delta$ $1.31\left(3 \mathrm{H}, \mathrm{t}, J=8.0 \mathrm{~Hz}, \mathrm{CO}_{2} \mathrm{CH}_{2} \mathrm{CH}_{3}\right), 2.10(2 \mathrm{H}, \mathrm{t}, J=8.0 \mathrm{~Hz}$, $\left.-\mathrm{CH}_{2}{ }^{-}\right), 3.74\left(3 \mathrm{H}, \mathrm{s}, \mathrm{OCH}_{3}\right), 3.90\left(2 \mathrm{H}, \mathrm{t}, J=8.0 \mathrm{~Hz},-\mathrm{CH}_{2}^{-}\right)$, $4.08\left(2 \mathrm{H}, \mathrm{t}, J=8.0 \mathrm{~Hz},-\mathrm{CH}_{2}-\right), 4.34(2 \mathrm{H}, \mathrm{q}, J=8.0 \mathrm{~Hz}$, $\left.\mathrm{CO}_{2} \mathrm{CH}_{2} \mathrm{CH}_{3}\right), 6.98(2 \mathrm{H}, \mathrm{dd}, J=4.0,8.0 \mathrm{~Hz}, \mathrm{Ar}-\mathrm{H}), 7.08(1 \mathrm{H}$, $\mathrm{d}, J=8.0 \mathrm{~Hz}, \mathrm{Ar}-\mathrm{H}), 7.37-7.42(3 \mathrm{H}, \mathrm{m}, \mathrm{Ar}-\mathrm{H}), 7.61(1 \mathrm{H}, \mathrm{d}$, $J=4.0 \mathrm{~Hz}, \mathrm{Ar}-\mathrm{H}), 8.02-8.06(2 \mathrm{H}, \mathrm{m}, \mathrm{Ar}-\mathrm{H}), 13.42(1 \mathrm{H}, \mathrm{s}$, $\mathrm{NOH})$. ESI-MS m/z: $555[\mathrm{M}+\mathrm{Na}]^{+}$.

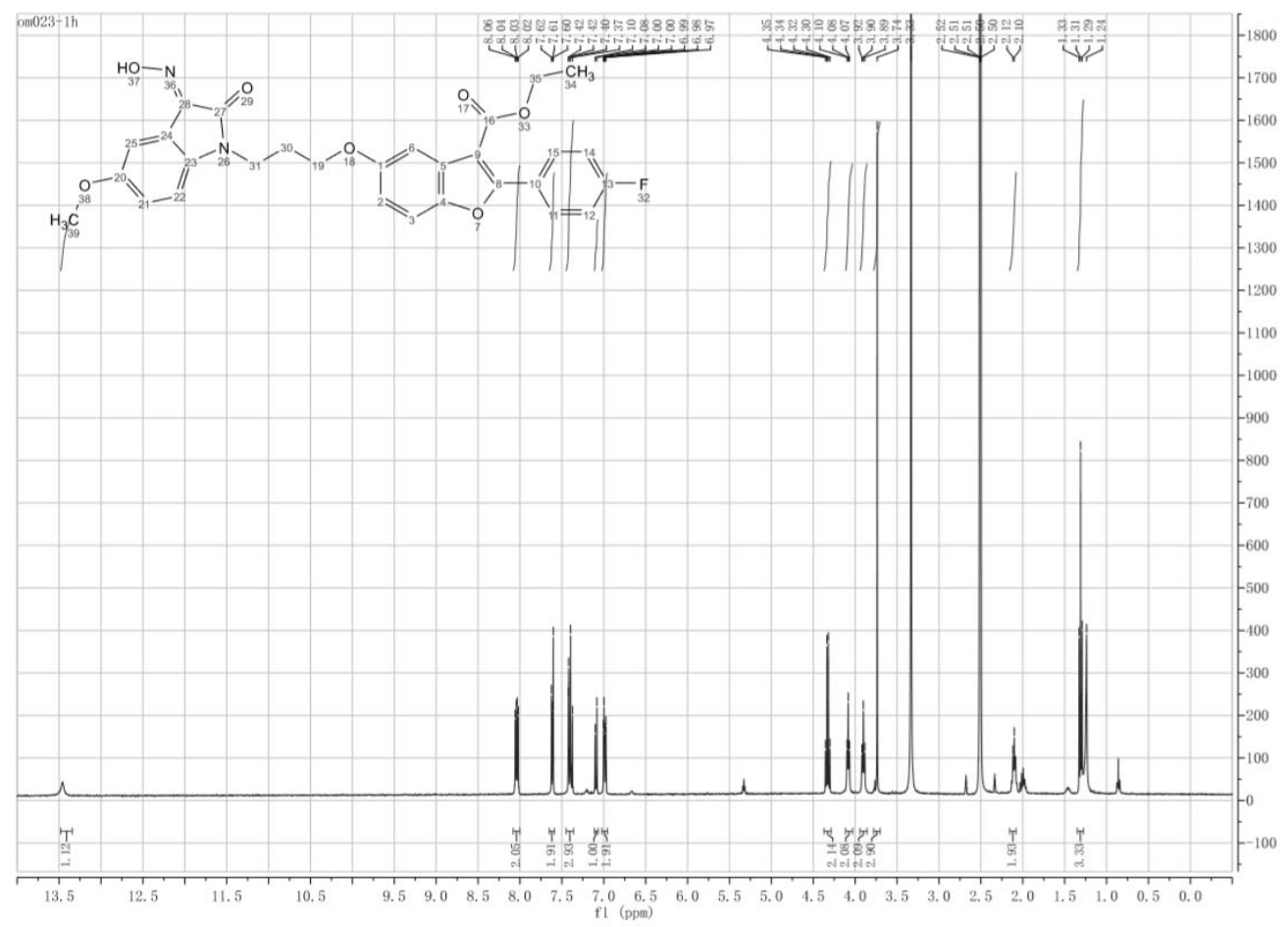


Ethyl2-(4-fluorophenyl)-5-(4-(3-(hydroxyimino)-5-methoxy-2oxoindolin-1-yl)butoxy)benzofuran-3-carboxylate (6x)

Yellow solid, yield: $28 \% .{ }^{1} \mathrm{H}$ NMR $\left(400 \mathrm{MHz}, \mathrm{DMSO}-d_{6}\right) \delta$ $1.31\left(3 \mathrm{H}, \mathrm{t}, J=8.0 \mathrm{~Hz}, \mathrm{CO}_{2} \mathrm{CH}_{2} \mathrm{CH}_{3}\right), 2.10(2 \mathrm{H}, \mathrm{t}, J=8.0 \mathrm{~Hz}$, $\left.-\mathrm{CH}_{2}-\right), 3.74\left(3 \mathrm{H}, \mathrm{s}, \mathrm{OCH}_{3}\right), 3.90\left(2 \mathrm{H}, \mathrm{t}, J=8.0 \mathrm{~Hz},-\mathrm{CH}_{2^{-}}\right)$, $4.08\left(2 \mathrm{H}, \mathrm{t}, J=8.0 \mathrm{~Hz},-\mathrm{CH}_{2}-\right), 4.34(2 \mathrm{H}, \mathrm{q}, J=8.0 \mathrm{~Hz}$, $\left.\mathrm{CO}_{2} \mathrm{CH}_{2} \mathrm{CH}_{3}\right), 6.98(2 \mathrm{H}, \mathrm{dd}, J=4.0,8.0 \mathrm{~Hz}, \mathrm{Ar}-\mathrm{H}), 7.08(1 \mathrm{H}$, $\mathrm{d}, J=8.0 \mathrm{~Hz}, \mathrm{Ar}-\mathrm{H}), 7.37-7.42(3 \mathrm{H}, \mathrm{m}, \mathrm{Ar}-\mathrm{H}), 7.61(1 \mathrm{H}, \mathrm{d}$, $J=4.0 \mathrm{~Hz}, \mathrm{Ar}-\mathrm{H}), 8.02-8.06(2 \mathrm{H}, \mathrm{m}, \mathrm{Ar}-\mathrm{H}), 13.42(1 \mathrm{H}, \mathrm{s}$, $\mathrm{NOH})$. ESI-MS m/z: $569[\mathrm{M}+\mathrm{Na}]^{+}$.

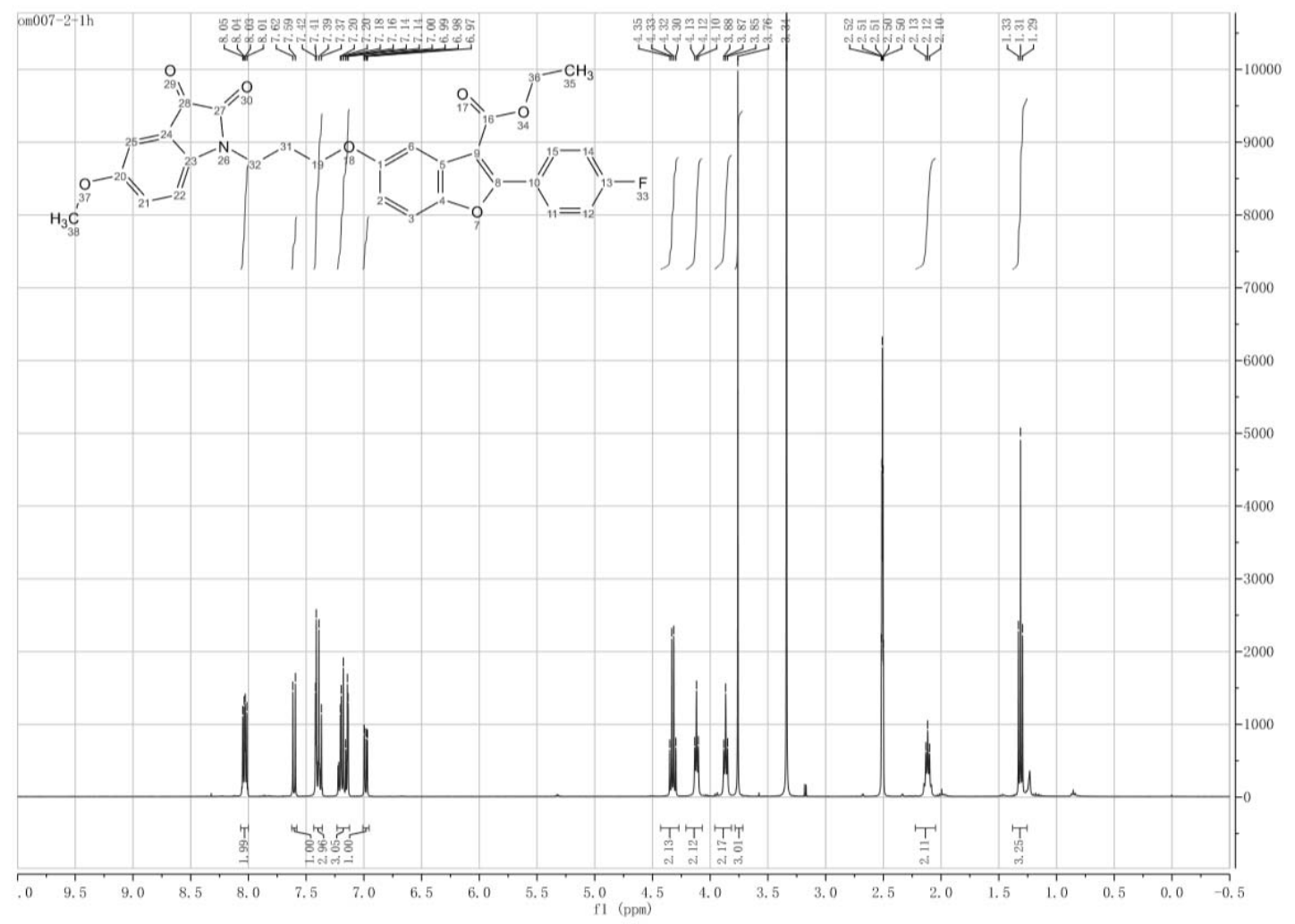

\section{CONCLUSION}

In conclusion, twenty-four novel benzofuranisatin hybrids 6a-x tethered via different length alkyl linkers were designed, synthesized and evaluated for their in vitro anti-bacterial activities against a panel of clinically important pathogens. All hybrids displayed decent in vitro anti-bacterial activities against both drug-sensitive and drugresistant Gram-positive and Gram-negative bacteria, have the potential to treat infections caused by various pathogens. In particular, the most active hybrid $\mathbf{6} \mathbf{1}$ was not only comparable to vancomycin against the majority of the tested Gram-positive strains, but also highly active against Gram-negative bacteria. Based on the above results, hybrid $\mathbf{6} \mathbf{1}$ could act as a lead for further optimization.

\section{REFERENCES}

1. G. F. Zhang, S. Zhang, B. F. Pan, X. F. Liu and L. S. Feng, Eur. J. Med. Chem., 2018, 144, 710-723.
2. Z. Xu, S. J. Zhao, Z. S. Lv, F. Zhang, F. Gao and L. Y. Bai, Eur. J. Med. Chem., in press.

3. C. Gao, Y. L. Fan, F. Zhao, Q. C. Ren, X. Wu, L. Chang and F. Gao, Eur. J. Med. Chem., 2018, 157, 1081-1095.

4. F. Gao, P. Wang, H. Yang, Q. Miao, L. Ma and G. M. Lu, Eur. J. Med. Chem., 2018, 157, 1223-1248.

5. I. N. Gaisina, F. Gallier, A. V. Ougolkov, K. H. Kim, T. Kurome, S. Guo, D. Holzle, D. N. Luchini, S. Y. Blond, D. D. Billadeau and A. P. Kozikowski, J. Med. Chem., 2009, 52, 1853-1863.

6. H. Singh, J. V. Singh, M. K. Gupta, A. K. Saxena, S. Sharma, K. Nepali, P. M. S. Bedi, Bioorg. Med. Chem. Lett. 2017, 27, 3974-3979;

7. M. Zhong, E. Peng, N. Huang, Q. Huang, A. Quq, M. Lau, R. Colonno and L. Li, Bioorg. Med. Chem. Lett., 2018, 28, 963-968.

8. G. Deepti, K. Amandeep and G. Bhupesh, Chem. Med. Chem., 2018, 13, 1275-1299.

9. Z. Xu, S. Zhang, C. Gao, F. Zhao, Z. S. Lv and L. S. Feng, Chin. Chem. Lett., 2017, 28, 159-167.

10. S. Zhang, Z. Xu, C. Gao, Q. C. Ren, L. Chang, Z. S. Lv, L. S. Feng, Eur. J. Med. Chem. 2017, 138, 501-513;

11. H. Khanam, and S. Uzzaman, Eur. J. Med. Chem., 2015, 97, 483-504.

12. Z. Xu, S. J. Zhao, Z. S. Lv, Y. L. Wang, L. Y. Bai and J. L. Deng, Eur. J. Med. Chem., in press.

13. J. H. Xu, Y. L. Fan and J. Zhou, J. Heterocyclic Chem., 2018, 55, 1854-1862. 
14. Y. Q. Hu, S. Zhang, Z. Xu, Z. S. Lv, M. L. Liu and L. S. Feng, Eur. J. Med. Chem., 2017, 141, 335-345.

15. F. Gao, H. Yang, T. Y. Lu, Z. J. Chen, L. Ma, Z. Xu and G. M. Lu, Eur. J. Med. Chem., 2018, 159, 277-281.

16. A. Aggarwal, M. K. Parai, N. Shetty, D. Wallis, L. Woolhiser, C. Hastings, N. K. Dutta, S. Galaviz, R. C. Dhakal, R. Shrestha, S. Wakabayashi, C. Walpole, D. Matthews, D. Floyd, P. Scullion, J. Riley, O. Epemolu, S.
Norval, T. Snavely, G. T. Robertson, E. J. Rubin, T. R. Loerger, F. A. Sirgel, R. vam der Merwe, P. D. van Helden, P. Keller, E. C. Böttger, P. C. Karakousis, A. J. Lenaerts and J. C. Sacchettini, Cell, 2017, 170, 249-259.

17. Z. Xu, X. F. Song, Y. Q. Hu, M. Qiang and Z. S. Lv, Eur. J. Med. Chem., 2017, 138, 66-71.

18. Z. Xu, S. Zhang, X. F. Song, M. Qiang and Z. S. Lv, Bioorg. Med. Chem. Lett., 2017, 27, 3643-3646. 